J. Lake Sci.(湖泊科学), 2019, 31(2): 573-589

DOI 10. 18307/2019. 0225

(c) 2019 by Journal of Lake Sciences

\title{
2000 年以来青藏高原湖泊面积变化与气候要素的响应关系”
}

\author{
问 利 ${ }^{1}$, 张廷斌 ${ }^{1,2 * *}$, 易桂花 ${ }^{3}$, 苗加庆 ${ }^{2,4}$, 李景吉 ${ }^{5,6}$, 别小娟 ${ }^{1}$, 黄祥麟 ${ }^{1}$ \\ (1:成都理工大学地球科学学院,成都 610059) \\ (2: 成都理工大学工程技术学院,乐山 614000) \\ (3: 成都理工大学管理科学学院, 成都 610059) \\ (4:蒙大拿大学物理工程系,美国蒙大拿州 59801) \\ (5: 成都理工大学环境与土木工程学院,成都 610059) \\ (6: 成都理工大学生态资源与景观研究所, 成都 610059)
}

\begin{abstract}
摘 要: 青藏高原星罗密布的湖泊对气候变化十分敏感, 在自然界水循环和水平衡中发挥着重要作用. 以 MODIS MOD09A1 和 SRTM DEM 为数据源, 提取了 2000-2016 年青藏高原丰水期面积大于 $50 \mathrm{~km}^{2}$ 的湖泊边界, 从内外流分区、 湖泊主要补给来源和湖水矿化度三个方面对 2000 年以来湖泊面积变化进行分析, 并结合青藏高原近 36 年气象数据, 根 据气象要素变化趋势分区, 初步探讨青藏高原湖泊面积变化与气候要素的关系. 结果表明: 青藏高原面积大于 $50 \mathrm{~km}^{2}$ 的 138 个湖泊整体扩张趋势显著, 总面积增加 $2340.67 \mathrm{~km}^{2}$, 增长率为 $235.52 \mathrm{~km}^{2} / \mathrm{a}$. 其中, 扩张型湖泊占 $67.39 \%$, 萎缩型湖 泊占 $12.32 \%$, 稳定型湖泊占 $20.29 \%$. 内流湖扩张趋势显著, 外流湖扩张趋势较明显; 以冰雪融水为主要补给来源的湖泊 整体扩张趋势明显, 以地表径流和河流补给为主要补给源的湖泊也呈扩张趋势; 盐湖和咸水湖以扩张为主, 淡水湖的扩 张、萎缩和稳定三种类型较均衡. 在青藏高原气候暖湿化方向发展背景下, 湖泊面积变化与气候要素具有显著的区域相 关性. 气温和降水变化趋势分区结果表明,气温增加、降水增加强趋势的高原 I 区湖泊扩张程度 $(78.18 \%)$ 依次大于气温 降低、降水量呈增加趋势的 V 区 $(66.67 \%)$, 气温、降水量呈增加趋势的 II 区 $(60.78 \%)$, 气温呈降低、降水量呈增加强趋势 的 IV 区 $(58.83 \%)$ 和气温呈增加、降水量呈减少趋势的 III 区 $(50.00 \%)$. 湖泊面积变化对气候变化响应研究表明, 升温引起 的冰雪融水补给对 I 区、II 区和 III 区湖泊面积扩张的影响显著, 加之降水量的增加, 湖泊扩张速率明显; IV 区和 V 区湖泊 面积扩张主要受降水量增加影响显著. 整体而言, 气温主要影响以冰雪融水为主要补给来源的湖泊, 降水量主要影响以 降水和地表径流为主要补给来源的湖泊.
\end{abstract}

关键词: 青藏高原; 湖泊面积;气候变化; MODIS; 遥感

\section{Changes of lake areas and its response to the climatic factors in Tibetan Plateau since 2000}

LV Li $^{1}$, ZHANG Tingbin ${ }^{1,2 * *}$, YI Guihua ${ }^{3}$, MIAO Jiaqing ${ }^{2,4}$, LI Jingji ${ }^{5,6}$, BIE Xiaojuan ${ }^{1}$ \& HUANG Xianglin ${ }^{1}$

(1: College of Earth Science, Chengdu University of Technology, Chengdu 610059, P.R. China)

(2: The Engineering \& Technical College of Chengdu University of Technology, Leshan 614000, P.R.China)

(3: College of Management Science, Chengdu University of Technology, Chengdu 610059, P.R. China)

(4: Department of Geophysical Engineering, Montana Tech of the University of Montana, Butte, MT 59801, USA)

(5: Chengdu University of Technology, College of Environmental and Civil Engineering Institute, Chengdu 610059, P.R.China)

(6: Chengdu University of Technology, Institute of Ecological Resource and Landscape, Chengdu 610059, P.R.China)

Abstract: Plenty of lakes in the Tibetan Plateau are sensitive to climate change and play an important role in the natural of water

* 国家自然科学基金项目 (41501060,41801099)、四川省自然科学重点项目 (18ZA0042) 和中国地质调查局项目 (DD20160015-26) 联合资助. 2018-06-03 收稿;2018-07-20 收修改稿. 闾利 (1992 ), 女, 硕士; E-mail:lvlikkll@ 163.com.

** 通信作者;E-mail :zhangtb@ cdut.edu.cn. 
cycle and water balance. Using MODIS MOD09A1 and SRTM DEM as data sources, the lake boundary over $50 \mathrm{~km}^{2}$ in high flow period in the Tibetan Plateau are extracted from 2000 to 2016. The patterns and trends of lake area changes are analyzed in the respects of internal and external flow zoning, main sources of recharge, and the salinity of the lakes since 2000. Meanwhile, combining with meteorological data in Tibetan Plateau in recent 36 years, according to the meteorological elements zoning of change trend, the relationship between the lake area changes and the climatic factors is primary discussed in Tibetan Plateau. The main conclusions are as follows: 138 lakes more than $50 \mathrm{~km}^{2}$ are overall tend to expand significantly, with $2340.67 \mathrm{~km}^{2}$ increased in area and a growth rate of $235.52 \mathrm{~km}^{2} / \mathrm{a}$. Among them, dilated lakes, shrinked lakes and stable lakes are accounted for $67.39 \%$, $12.32 \%$ and $20.29 \%$, respectively. The expansion trend of inflow lakes is significant, while the outflow lakes is less significant. Lakes with glacier water as the main source of recharge is expanded significantly, so do lakes with surface runoff and river recharge as main sources. Saline and semi-saline lakes also exhibit a trend of expansion. As for the freshwater lakes, the three types of expansion, atrophy, and stabilization are relatively balanced. The climate of the Tibetan Plateau presents a warmer and more humid tendency. Meanwhile, there are distinguished regional correlation between lake area changes and climate change. The results of change trend zoning of air temperature and precipitation indicate that the degree of lake expansion of Zone I where air temperature and precipitation are increasing significantly is greater than that of Zone $\mathrm{V}$ where air temperature decreases and precipitation increases. In turn, Zone II with increasing air temperature and precipitation, Zone IV in which air temperature is decreasing and precipitation is increasing, and Zone III with increasing air temperature and decreasing precipitation in Tibetan Plateau. The recharge of glacier melt water caused by air temperature rise has a significant effect on the expansion of lake area in Zone I , II , and III. In addition, the rate of lake expansion is significantly increasing due to the increase of precipitation. The lake area expansion in Zone IV and V is mainly affected by the increase of precipitation. On the whole, air temperature mainly affects lakes with glacier melt water as the main source of recharge and precipitation mainly affects lakes with precipitation and surface runoff as the main sources of recharge.

Keywords: Tibetan Plateau; lake area; climate change; MODIS; remote sensing

青藏高原作为地球第三极核心区 ${ }^{[1-2]}$, 是全国数量最多、面积最大的湖泊分布区, 同时高原上蕴藏着除 两极之外最大的冰雪资源 ${ }^{[3]}$. 在全球气候变化背景下, 青藏高原的气候变化和冰川、湖泊变化受到气象、水 文和生态等领域学者的高度重视 ${ }^{[4-6]}$. 湖泊作为陆地水圈的组成部分, 参与自然界的水循环, 能够反映区域 气候与环境的变化状况, 是气候变化的指示器 ${ }^{[5,7-8]}$. 青藏高原分布着以盐湖和咸水湖为主的众多内陆湖泊, 成为独特的自然地理景观. 在区域和全球气候共同作用下, 青藏高原湖泊在水位 ${ }^{[9-10]}$ 、面积 ${ }^{[11-13]}$ 、数量 ${ }^{[14-15]}$ 和水量 ${ }^{[16-17]}$ 等方面正发生着不同程度的变化. 掌握青藏高原湖泊的动态变化特征对青藏高原区域气候变 化、水环境及生态安全等研究具有重要意义.

近年来, 已有大量关于青藏高原湖泊的研究. 间立娟等 ${ }^{[5]}$ 认为近 40 年来, 青藏高原的湖泊面积呈增加 趋势; 地质构造是影响湖泊变迁的主导因素, 而短时间尺度的湖泊变迁主要受气候因素的影响. Yi 等 ${ }^{[7-8]}$ 认 为申扎流域湖泊面积呈扩张趋势, 湖泊面积变化主要受气候暖湿化背景下的气温和降水影响, 而色林错面 积变化受热季气温影响显著. 董斯扬等 ${ }^{[13]} 、 \mathrm{Lei}$ 等 ${ }^{[18]}$ 和 $\mathrm{Li}$ 等 ${ }^{[19]}$ 认为青藏高原近 45 年来, 湖泊面积整体上呈 加速扩张趋势, 降水量是导致湖泊面积变化的主要驱动因子. Wan 等 ${ }^{[20]}$ 认为气候变暖导致的气温升高、降 水量增加、冰川融水增加等使 1975-2016 年那曲和可可西里地区的湖泊总体呈扩张趋势, 如色林错、纳木错 和赤布张错. Wang 等 ${ }^{[21]}$ 和 Jiang 等 ${ }^{[22]}$ 认为 2003-2015 年青藏高原大部分湖泊面积扩张主要是受气候变暖 的影响, 气温升高导致冰雪融化增加是湖泊面积扩张的主要驱动因子. 另外, 在湖泊面积监测与提取方法方 面, 大部分基于 Landsat 系列影像 ${ }^{[23-24]}$ 、CBERS 影像 ${ }^{[25-26]}$ 和高分影像 ${ }^{[15]}$ 等的研究时间间隔较长, 提取方 法 ${ }^{[27-30]}$ 较繁琐、通用性较差. 在讨论与气候的响应方面, 多集中于气候因子对高原湖泊的整体变化趋势分 析 ${ }^{[31-33]}$, 从湖泊不同特征角度讨论气候变化对高原湖泊影响方面, 如青藏高原湖泊内外流分区、湖泊不同补 给来源、湖泊矿化度分类等方面的研究相对较少. 为满足时间过程连续和空间分辨率一致的数据应用需求, 以中等空间分辨率 MODIS (Moderate Resolution Imaging Spectroradiometer) 遥感影像为数据源进行湖泊水面 提取成为当前研究的理想选择 ${ }^{[34-38]}$. 目前尚缺乏 2012 年之后基于 MODIS 的青藏高原湖泊面积最新数据, 致 使对区内气候变化背景下湖泊变化规律的认识尚不全面.

本文以 MODIS MOD09A1 产品为数据源, 提取了青藏高原 2000-2016 年间面积大于 $50 \mathrm{~km}^{2}$ 的湖泊, 基 
于湖泊内外流分区、湖泊不同补给方式和湖水矿化度分类开展湖泊面积变化研究, 以期分析、总结 2000 年 以来青藏高原湖泊面积变化特征. 同时, 结合 1980-2015 年间青藏高原气象数据, 首次基于气象因子变化 趋势分区初步探讨了青藏高原湖泊面积变化与气候要素的响应关系.

\section{1 研究区概况}

青藏高原 $\left(26^{\circ} 00^{\prime} \sim 39^{\circ} 46^{\prime} \mathrm{N}, 73^{\circ} 18^{\prime} \sim 104^{\circ} 46^{\prime} \mathrm{E}\right)$ 地域辽阔 ${ }^{[39]}$, 总面积约 261.5 万 $\mathrm{km}^{2}$, 平均海拔 $4000 \sim$ $5000 \mathrm{~m}$. 高原日照充足, 气温较低, 降水量自东南向西北逐渐减少, 气候类型复杂多样. 植被类型丰富, 边缘 高山环绕、峡谷深切, 内部由辽阔的高原、星罗棋布的湖盆和宽广的盆地等地貌组成. 同时, 青藏高原是我国 冰川和冻土最发育的地区, 分别约占我国冰川总面积的 $4 / 5$ 和全国冻土面积的 $70 \%{ }^{[40]}$. 据统计 ${ }^{[15]}$, 高原内 湖泊面积大于 $10 \mathrm{~km}^{2}$ 的有 419 个,总面积由 1960 年的 $36148.9 \mathrm{~km}^{2}$ 增长到 2014 年的 $43894.3 \mathrm{~km}^{2}$, 呈显著扩 张趋势. 该区域湖泊补给方式主要以冰川融水、大气降水和地表径流为主.

\section{2 数据与方法}

\subsection{MODIS 数据}

MODIS 是美国国家航空航天局 (National Aeronautics and Space Administration, NASA) 对地观测系统 (Earth Observation System, EOS) 搭载在 Terra 和 Aqua 卫星上的传感器, 分别于 1999 年 12 月 18 日和 2002 年 5 月 4 日发射. Terra 过境时间在当地上午 $10: 30$ 左右 (晚上 10:30), Aqua 在凌晨 $1: 30$ 左右(下午 $1: 30)^{[41]}$.

MODIS 数据来源于美国宇航局地球观测系统数据和信息系统 (NASA's Earth Observing System Data and Information System,EOSDIS) 的 MOD09A1 (https://ladsweb.modaps.eosdis.nasa.gov/search/) 3 级地表反射率数 据产品, 时间分辨率为 $8 \mathrm{~d}$, 空间分辨率为 $500 \mathrm{~m}$. 相关研究表明青藏高原丰水期主要为 $8 、 9$ 月 ${ }^{[20]}$, 本文选取 青藏高原每年 7-9 月影像 (即每年第 185 273 天数据) 作为基础数据, 获取了 2000-2016 年共 17 年 1632 景 MOD09A1 数据.

\subsection{DEM 数据}

DEM (Digital Elevation Model) 数据来自中国科学院计算机网络信息中心国际科学数据镜像网站 (http://www.gscloud.cn) 的 SRTM V3 版本 (Shuttle Radar Topography Mission Version 3), 空间分辨率为 $90 \mathrm{~m}$.

\section{3 近地表气象再分析数据}

近地表气象再分析数据来自寒区早区科学数据中心 ( http://westdc.westgis.ac.cn) 提供的中国区域高时 空分辨率地面气象要素驱动数据集 ${ }^{[42-43]}$, 包括青藏高原 1980-2015 年 7-9 月时间分辨率为 $3 \mathrm{~h}$, 空间分辨 率为 $0.1^{\circ}$ 的近地面气温和地面降水率数据.

\section{4 冰川数据}

冰川数据来自寒区早区科学数据中心提供的中国第二次冰川编目数据集 (The Second Glacier Inventory Dataset of China) 的 V1.0 版本 ${ }^{[44]}$,包括青藏高原 2006-2011 年逐条冰川信息的矢量数据和属性数据.

\section{5 湖泊面积提取方法}

MOD09A1 在近红外波段水体的反射率较低, 而水体附近的地物在近红外波段上反射率较高. 在近红外 波段水体与环境背景之间存在明显的反射率差异, 因此单波段阈值法可以获得较好的识别效果 ${ }^{[45]}$.

根据水体的光谱特性, 本文对 MOD09A1 band6 影像采用逐月合成消除云及其阴影的影响, 通过反复试 验, 在坡度 $<5^{\circ}$ 的条件下, 确定提取湖泊边界的最佳阈值消除山体阴影的影响, 最后通过目视方法对湖泊边 界进行检查和修正. 本文选择年内丰水期平均湖泊面积作为该年湖泊面积.

\section{3 结果与分析}

\section{1 本研究与前人成果对比}

小型湖泊的面积变化对区域环境的影响较小且受季节变化的影响较大 ${ }^{[13]}$, 故本文提取了青藏高原 2006-2011 年 17 年来面积连续大于 $50 \mathrm{~km}^{2}$ 的 138 个湖泊作为研究对象 (图 1), 统计了每年丰水期的平均 面积, 并沿用 Wan 等 ${ }^{[46]}$ 公布的湖泊数据集之湖名. 


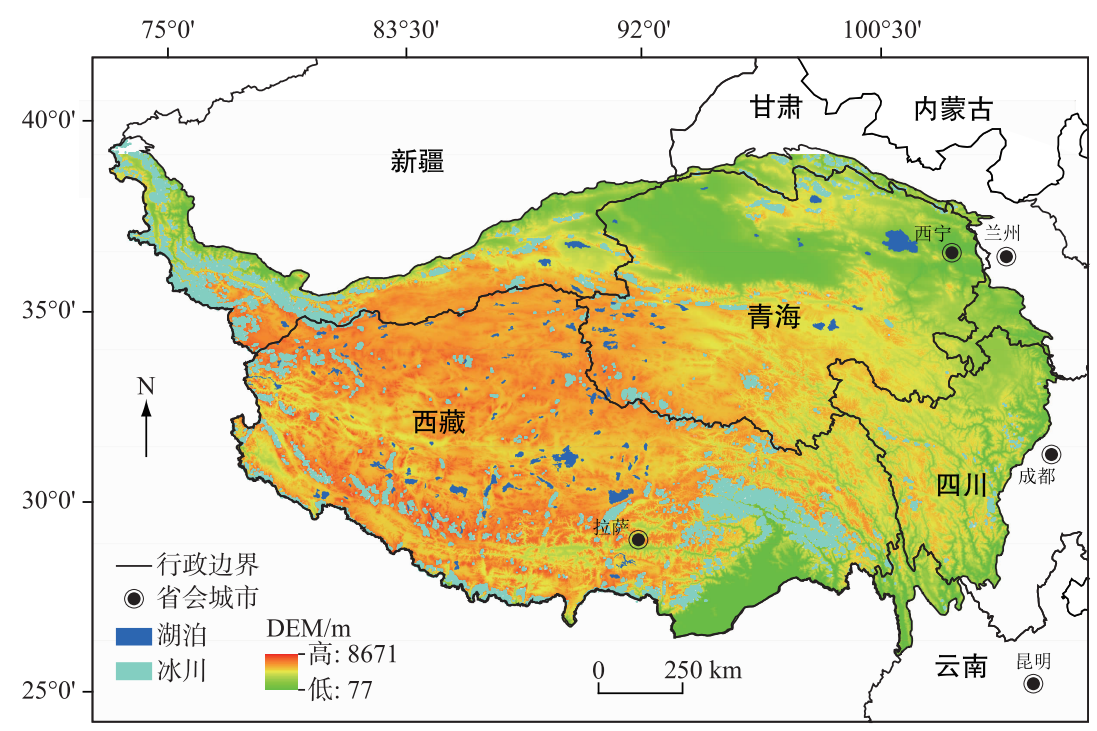

图 1 青藏高原面积大于 $50 \mathrm{~km}^{2}$ 的湖泊分布

Fig. 1 Distribution of lakes with an area of more than $50 \mathrm{~km}^{2}$ in the Tibetan Plateau

已有大量学者对青藏高原湖泊面积变化进行了研究. Wan 等 ${ }^{[46]}$ 公布了四期 $(2002 、 2005 、 2009$ 和 2014 年) 基于 Landsat、CBERS 和 GF-1 卫星影像通过目视解译方法得到的面积 $\geqslant 10 \mathrm{~km}^{2}$ 的青藏高原湖泊数据集. 图 2 为与 Wan 等提取的湖泊面积的对比结果, 使用决定系数 $\left(R^{2}\right)$ 、平均绝对误差 (Mean Absolute Error, $M A E$ ) 及标准差 (Standard Deviation, $S D$ ) 来定量评价提取的湖泊面积精度, 四组数据显示出很好的一致性 $\left(R_{2002}^{2}=0.9978, R_{2005}^{2}=0.9980, R_{2009}^{2}=0.9985, R_{2014}^{2}=0.9979\right)$. Yao 等 ${ }^{[47]}$ 利用 2000 年 Landsat TM $/ \mathrm{ETM}^{+}$遥感影 像获取了青藏高原可可西里地区大于 $10 \mathrm{~km}^{2}$ 的湖泊面积, 与本文提取结果对比相关性较高 $\left(R_{2000}^{2}=0.9774\right)$. 间立娟等 ${ }^{[5]}$ 利用 $1970 s 、 1990$ s、2000 年前后和 2010 年前后 Landsat TM/ETM 遥感影像提取了青藏高原所有 湖泊边界信息, 与本文结果对比相关性也较高 $\left(R_{2000}^{2}=0.9983, R_{2009}^{2}=0.9851\right)$. 本次提取的湖泊面积一般比 Wan 等和问立娟等提取的湖泊面积略大, 可能与卫星影像的获取时间有关. 文中影像获取时间为青藏高原 的丰水期,该时间段高原温度高、降水多,冰川处于消融状态, 是大多数湖泊面积的年最大状态.

\section{2 湖泊面积变化总体趋势}

为统计和研究不同湖泊面积变化趋势, 采用最小二乘法建立湖泊面积与年份的一元线性回归模型:

$$
y=\mathrm{a} \cdot x+\mathrm{b}
$$

式中, $y$ 表示面积, $x$ 表示对应年份, $\mathrm{a}$ 为斜率即面积变化趋势, $\mathrm{b}$ 表示截距, $\mathrm{a}$ 与 $\mathrm{b}$ 通过最小二乘法确定. 其中, 通过 0.05 显著性检验的湖泊 95 个, 通过 0.01 显著性检验的湖泊 81 个; 相关系数 $R^{2}>0.5$ 的湖泊 70 个 (表 1 ).

当 $\mathrm{a}=0.17$ 时, 湖泊面积线性变化趋势的倾角约为 $10^{\circ}$, 研究时段内湖泊面积变化较小, 根据 $\mathrm{a}$ 值大小将 湖泊面积变化趋势划分为萎缩型、稳定型和扩张型 3 类 (表 2 ).

经统计,2000 以来青藏高原湖泊面积总体以扩张为主 ${ }^{[52-53]}\left(\mathrm{a}=235.52 \mathrm{~km}^{2} / \mathrm{a}, R^{2}=0.87\right.$ ) (图 3a), 与扩张 型湖泊面积变化趋势相似, 主要原因是扩张型湖泊面积占主导地位. 扩张型湖泊 93 个, 年际面积线性变化 趋势明显 $\left(\mathrm{a}=255.57 \mathrm{~km}^{2} / \mathrm{a}, R^{2}=0.93\right)$ (图 3b), 湖泊面积在 2001 年最小. 其中, 扩张型湖泊在 2009 年后面 积增长趋势变缓. 色林错 $\left(\mathrm{a}=23.39 \mathrm{~km}^{2} / \mathrm{a}, R^{2}=0.90\right)$ 、阿雅格库 $\left(\mathrm{a}=22.10 \mathrm{~km}^{2} / \mathrm{a}, R^{2}=0.98\right)$ 、青海湖 $(\mathrm{a}=$ $\left.10.24 \mathrm{~km}^{2} / \mathrm{a}, R^{2}=0.67\right)$ 等湖泊面积呈显著扩张趋势. 萎缩型湖泊 17 个, 年际面积变化较大 $(\mathrm{a}=-18.62$ $\left.\mathrm{km}^{2} / \mathrm{a}, R^{2}=0.62\right)$ (图 3c), 2005 年后湖泊面积波动下降趋势增强. 霍鲁诺尔 $\left(\mathrm{a}=-6.59 \mathrm{~km}^{2} / \mathrm{a}, R^{2}=0.56\right)$ 、羊 卓雍错 $\left(\mathrm{a}=-5.37 \mathrm{~km}^{2} / \mathrm{a}, R^{2}=0.61\right)$ 等湖泊面积呈显著萎缩趋势. 稳定型湖泊 28 个, 湖泊面积变化线性趋势 不明显 $\left(\mathrm{a}=-1.43 \mathrm{~km}^{2} / \mathrm{a}, R^{2}=0.02\right)$ (图 3d), 年际以波动变化为主, 2007-2014 年间波动较明显. 泽错 $(\mathrm{a}=$ 

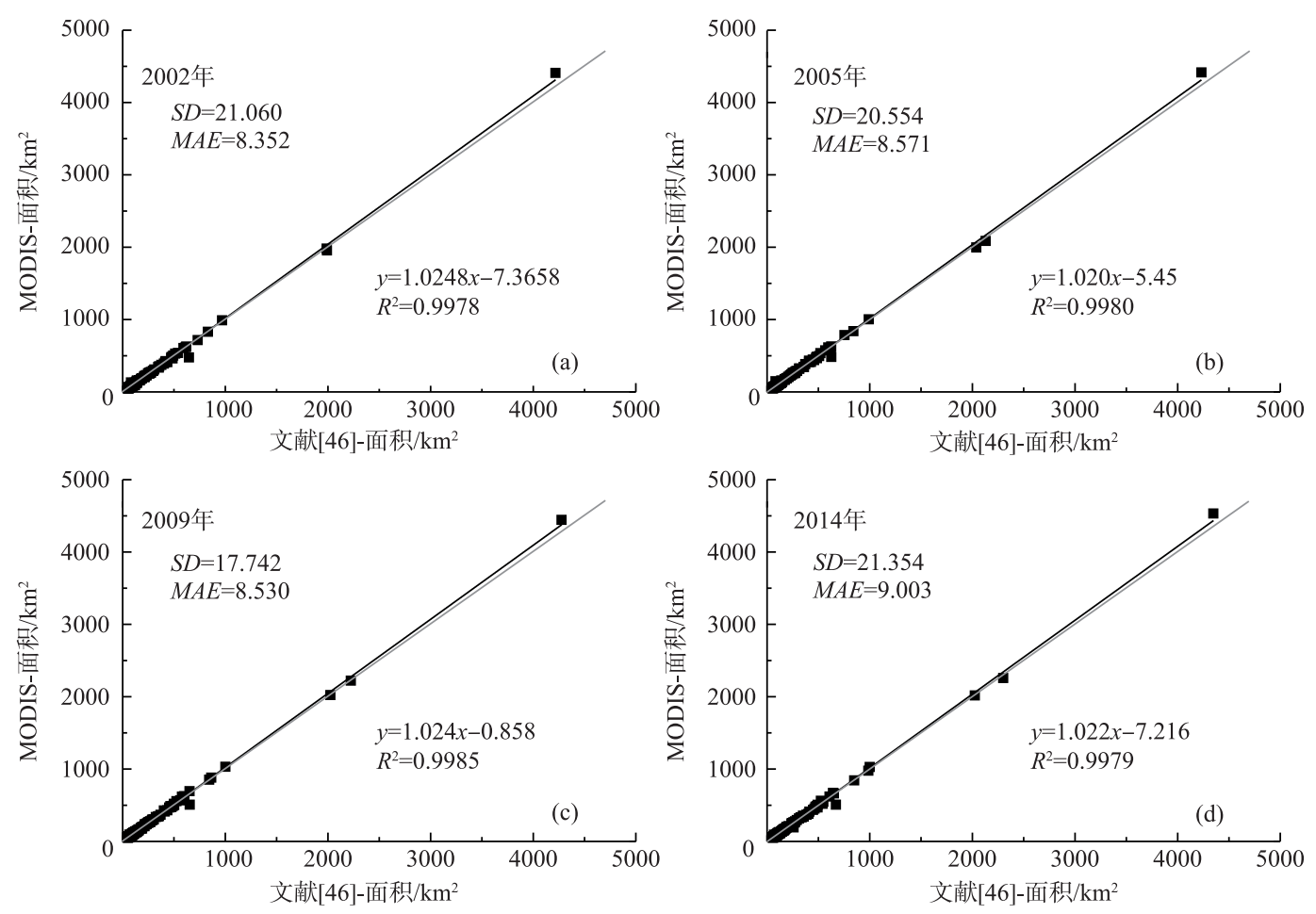

图 2 青藏高原 138 个湖泊与文献 [ 46]对应数据集中湖泊面积的相关性

Fig. 2 Comparison of the 138 lakes in this study and the literature [46] results in the Tibetan Plateau

$\left.0.17 \mathrm{~km}^{2} / \mathrm{a}, R^{2}=0.18\right)$ 、拜惹布错 $\left(\mathrm{a}=0.02 \mathrm{~km}^{2} / \mathrm{a}, R^{2}=0.00\right)$ 等湖泊面积保持相对稳定. 其中, 面积变化较明 显的 110 个( $|\mathrm{a}|>0.17$ ) 湖泊中, 色林错、阿雅格库、阿其克库勒湖 ( $\mathrm{a}=12.27 \mathrm{~km}^{2} / \mathrm{a}, R^{2}=0.98$ )、乌兰乌拉湖 $\left(\mathrm{a}=8.81 \mathrm{~km}^{2} / \mathrm{a}, R^{2}=0.92\right)$ 、多格错仁强错 $\left(\mathrm{a}=8.33 \mathrm{~km}^{2} / \mathrm{a}, R^{2}=0.96\right) 、$ 碱水湖 $\left(\mathrm{a}=7.81 \mathrm{~km}^{2} / \mathrm{a}, R^{2}=0.98\right) 、$ 西 金乌兰湖 $\left(\mathrm{a}=7.12 \mathrm{~km}^{2} / \mathrm{a}, R^{2}=0.94\right)$ 和阿克萨依湖 $\left(\mathrm{a}=6.56 \mathrm{~km}^{2} / \mathrm{a}, R^{2}=0.92\right)$ 等湖泊面积线性变化趋势最为 显著.

\section{3 湖泊面积变化分类分析}

3.3.1 按湖泊内外流分区 湖泊是地表水体和江河水系的重要组成部分. 按照河川径流的循环形式,把河流 区分为注人海洋的外流流域 (或外流区) 和不与海洋直接沟通的内流流域 (或内流区) 两大类. 我国外流区 和内流区分别约占全国总面积的 $64 \%$ 和 $36 \%{ }^{[48]}$. 与内外流分区相对应, 分布于两大流域类型内的湖泊,则 分别称为内流湖和外流湖 ${ }^{[48]}$. 青藏高原的内流湖又多为闭流湖.

青藏高原湖泊以内流湖为主, 本次统计的青藏高原内流湖 131 个(占比 $94.93 \%$ ). 2000 年以来内流湖总面 积呈显著扩张趋势 ( $\mathrm{a}=230.65 \mathrm{~km}^{2} / \mathrm{a}, R^{2}=0.88$ ) (图 4a), 主要原因是扩张型湖泊数量多、面积大. 年均总面积 为 $32143.53 \mathrm{~km}^{2}, 2001$ 年面积最小, 2016 年达面积最大值. $2001-2009$ 年内流湖湖泊面积增长速率 $(\mathrm{a}=364.58$ $\left.\mathrm{km}^{2} / \mathrm{a}\right)$ 大于 $2010-2016$ 年湖泊面积增长速率 $\left(111.25 \mathrm{~km}^{2} / \mathrm{a}\right)$. 外流湖 7 个,整体亦具增长趋势 $(\mathrm{a}=4.87$ $\mathrm{km}^{2} / \mathrm{a}, R^{2}=0.21$ ) (图 4b), 年均面积为 $1885.99 \mathrm{~km}^{2} .2000-2003$ 年外流湖总面积呈现萎缩趋势, 之后面积快速 增加, 到 2009 年总面积达到最大, 之后呈现波动减少趋势. 其中 7 个外流湖中有 3 个湖泊呈现扩张趋势 (鄂陵 湖、扎陵湖、帕龙错), 3 个湖泊表现为稳定趋势 (玛章错钦、错那、叶鲁苏湖), 1 个湖泊呈现萎缩趋势 (森里错).

中国最大的咸水湖——青海湖, 属于典型的内流型湖泊. 提取结果显示, 2000 年以来青海湖湖泊面积整 体呈扩张趋势. 2000-2005 年, 湖泊面积萎缩. 2005 年之后, 青海湖面积开始进人持续增长期, 且远远超过 2000 年的面积, 与前人研究结果一致 ${ }^{[40,54]}$. 多数研究认为, 青藏高原气候从暖干化向暖湿化转变, 布哈河冰 雪融水补给量和流域降水量增加导致人湖径流量明显增加 ${ }^{[54-55]}$, 成为青海湖面积持续增长的主要原因. 
表 12000 年以来青藏高原 138 个湖泊面积变化趋势统计

Tab. 1 Area changes of 138 lakes in the Tibetan Plateau since 2000

\begin{tabular}{|c|c|c|c|c|c|c|c|c|c|c|c|}
\hline 湖泊 & a & $R^{2}$ & $\begin{array}{l}\text { 主要补给 } \\
\text { 源 }^{48-51]}\end{array}$ & 湖泊 & a & $R^{2}$ & $\begin{array}{l}\text { 主要补给 } \\
\text { 源 }^{448-51]}\end{array}$ & 湖泊 & a & $R^{2}$ & $\begin{array}{l}\text { 主要补给 } \\
\text { 源 [48-51] }\end{array}$ \\
\hline 错那 & 0.15 & 0.02 & (1) & 明镜湖 & 3.48 & 0.96 & (2) & 窝尔巴错 & -0.06 & 0.01 & - \\
\hline 羊湖 & 6.23 & 0.98 & (1) & 吴如错 & -0.79 & 0.35 & (3) (4) & 独立石湖 & 1.37 & 0.96 & (3) \\
\hline 泽错 & 0.17 & 0.18 & (1) & 木纠错 & -0.31 & 0.37 & (3) & 多格错仁 & 5.76 & 0.44 & (1) \\
\hline 吐错 & 3.24 & 0.86 & (4) & 向阳湖 & 1.75 & 0.94 & (1) & 茶卡盐湖 & 0.32 & 0.04 & (4) \\
\hline 懂错 & 0.69 & 0.55 & (2) & 许如错 & -0.17 & 0.12 & (1) & 赤布张错 & 3.83 & 0.71 & (1) \\
\hline 蓬错 & 1.33 & 0.61 & (2) & 雪景湖 & 1.47 & 0.96 & (2) & 小柴旦湖 & 1.86 & 0.58 & (4) \\
\hline 错尼 & 6.13 & 0.94 & (3) & 雪莲湖 & 0.29 & 0.36 & (2) & 错达日玛 & 1.63 & 0.96 & (2) \\
\hline 洞错 & 1.36 & 0.83 & (2) & 鄂陵湖 & 3.36 & 0.36 & (2)(4) & 当惹雍错 & 0.89 & 0.28 & (1) \\
\hline 崩错 & -0.03 & 0.00 & (1) & 饮马湖 & -0.12 & 0.02 & (1) & 叶鲁苏湖 & -0.07 & 0.00 & (3) \\
\hline 错鄂 1 & -0.82 & 0.34 & (4) & 永红湖 & 1.07 & 0.67 & (1) (4) & 雅个冬错 & 3.72 & 0.71 & (3) (4) \\
\hline 错鄂 2 & 0.52 & 0.32 & (2) & 玉液湖 & 2.73 & 0.86 & (1) & 雅根错 1 & 2.87 & 0.90 & (3) \\
\hline 班公错 & 1.86 & 0.42 & (1) & 越恰错 & -0.07 & 0.05 & (3) & 阿雅格库 & 22.10 & 0.98 & (1) (4) \\
\hline 阿果错 & -0.27 & 0.34 & (2) & 果忙错 & 0.62 & 0.55 & (2) & 依布茶卡 & 0.90 & 0.64 & (1) (4) \\
\hline 骆驼湖 & 1.81 & 0.46 & (4) & 果普错 & 0.18 & 0.08 & - & 戈木茶卡 & 0.29 & 0.40 & (4) \\
\hline 阿鲁错 & 0.00 & 0.00 & (1) & 哈拉湖 & 1.23 & 0.67 & (1) (4) & 黑石北湖 & 0.96 & 0.71 & (1) \\
\hline 库赛湖 & 5.48 & 0.83 & (1) & 格仁错 & -0.54 & 0.19 & (4) & 霍鲁诺尔 & -6.59 & 0.56 & (3) \\
\hline 阿翁错 & 0.29 & 0.25 & (1) (4) & 公珠错 & -0.07 & 0.06 & (2) & 结则茶卡 & 0.37 & 0.66 & (4) \\
\hline 扎陵湖 & 1.57 & 0.37 & (2) (4) & 碱水湖 & 7.81 & 0.98 & (1) & 玛章错钦 & -0.03 & 0.00 & (3) \\
\hline 帕度错 & 1.25 & 0.85 & (1) & 杰萨错 & -0.01 & 0.00 & (1) & 普莫雍错 & 0.28 & 0.07 & (1) (4) \\
\hline 昂孜错 & 3.57 & 0.90 & (3) & 郭扎错 & -0.47 & 0.36 & (1) & 拜惹布错 & 0.02 & 0.00 & (1) \\
\hline 巴木错 & 2.77 & 0.74 & (1) (4) & 鲸鱼湖 & 5.59 & 0.96 & (1) (2) & 昂拉仁错 & -0.30 & 0.03 & (1) \\
\hline 朋彦错 & 1.11 & 0.90 & (4) & 可考湖 & 1.24 & 0.83 & (1) (4) & 仁错贡玛 & 0.85 & 0.19 & - \\
\hline 达瓦错 & 1.26 & 0.90 & (2) & 拉果错 & 0.18 & 0.19 & (1) (4) & 兹格塘错 & 1.78 & 0.83 & (3) \\
\hline 邦达错 & 2.06 & 0.92 & (3) & 振泉湖 & 5.18 & 0.88 & (3) & 乃日平错 & 0.38 & 0.21 & (2) \\
\hline 班戈错 & -0.35 & 0.02 & (3) & 美马错 & 2.33 & 0.94 & (1) & 诺尔玛错 & 0.84 & 0.76 & (1) (4) \\
\hline 波涛湖 & -0.09 & 0.04 & (1) & 麦穷错 & -0.31 & 0.18 & (2) & 克鲁克湖 & -0.14 & 0.12 & (2) \\
\hline 布若错 & -0.06 & 0.02 & (1) & 其香错 & 1.66 & 0.81 & (3) & 马而下错 & 0.88 & 0.76 & (2) \\
\hline 仓木错 & 0.39 & 0.50 & (3) & 恰归错 & -0.10 & 0.04 & - & 玛旁雍错 & -0.14 & 0.11 & (4) \\
\hline 拉昂错 & -0.74 & 0.38 & (2) & 青海湖 & 10.24 & 0.67 & (3) & 勒斜武担错 & 2.95 & 0.90 & (1) \\
\hline 朝阳湖 & -0.34 & 0.02 & - & 清澈湖 & 0.75 & 0.77 & (1) & 嘎尔孔茶卡 & 1.16 & 0.83 & (4) \\
\hline 鄂雅错 & 2.02 & 0.88 & (1) (4) & 雀莫错 & 0.86 & 0.85 & (1) & 仁青休布错 & 0.01 & 0.00 & (1) \\
\hline 令果错 & 0.97 & 0.83 & (1) & 孜桂错 & -0.24 & 0.32 & (3) (4) & 斯潘古尔湖 & 0.01 & 0.00 & (1) \\
\hline 帕龙错 & 0.19 & 0.20 & (1) & 万泉湖 & -0.39 & 0.41 & - & 鲁玛江冬错 & 1.94 & 0.64 & (1) \\
\hline 佩古错 & -0.51 & 0.32 & (3) & 榴弹湖 & -0.17 & 0.11 & - & 阿克萨依湖 & 6.56 & 0.92 & (1) \\
\hline 森里错 & -0.30 & 0.10 & (1) & 若拉错 & 3.46 & 0.61 & - & 可可西里湖 & 3.44 & 0.88 & (1) \\
\hline 达如错 & 0.55 & 0.36 & (2) & 赛布错 & 1.68 & 0.92 & (4) & 玛尔盖茶卡 & 3.17 & 0.88 & (3) \\
\hline 戈芒错 & 0.53 & 0.19 & (4) & 色林错 & 23.39 & 0.90 & (3) & 玛尔果茶卡 & -0.14 & 0.15 & (3) \\
\hline 达则错 & 4.72 & 0.96 & (3) & 龙木错 & 0.32 & 0.41 & (4) & 尔斯库勒湖 & 0.63 & 0.27 & (3) \\
\hline 打加错 & -0.12 & 0.06 & - & 苏干湖 & 0.66 & 0.64 & (3) & 扎布耶茶卡 & 1.25 & 0.06 & (1)(2) \\
\hline 当穹错 & 0.61 & 0.83 & (2) & 塔若错 & -0.10 & 0.01 & (1) & 扎日南木错 & 2.06 & 0.50 & (1) \\
\hline 嘎仁错 & -0.14 & 0.17 & (2) & 太阳湖 & -0.05 & 0.01 & (1) & 冬给措纳湖 & 1.59 & 0.66 & (3) \\
\hline 得雨湖 & 0.28 & 0.37 & (2) & 托素湖 & 1.28 & 0.71 & (4) & 乌兰乌拉湖 & 8.81 & 0.92 & (3) \\
\hline 东卡错 & 1.05 & 0.61 & (2) & 羊卓雍错 & -5.37 & 0.61 & (2) & 西金乌兰湖 & 7.12 & 0.94 & (3) \\
\hline 纳木错 & 1.85 & 0.29 & (1) & 托和平错 & -0.09 & 0.07 & (1) (4) & 多格错仁强错 & 8.33 & 0.96 & (1) \\
\hline 拉雄错 & 0.59 & 0.90 & (1) & 特拉什湖 & 1.15 & 0.96 & (3) & 美日切错玛日 & 1.69 & 0.85 & - \\
\hline Noname_2 & 0.17 & 0.08 & - & 仁错约玛 & 0.51 & 0.46 & (4) & 阿其克库勒湖 & 12.27 & 0.98 & (1) \\
\hline
\end{tabular}

(1)表示冰雪融水补给; (2)表示地表径流补给; (3)表示河流补给; (4)表示其他;一表示文献中未给出补给方式; $\mathrm{a}$ 单位为 $\mathrm{km}^{2} / \mathrm{a}$. 

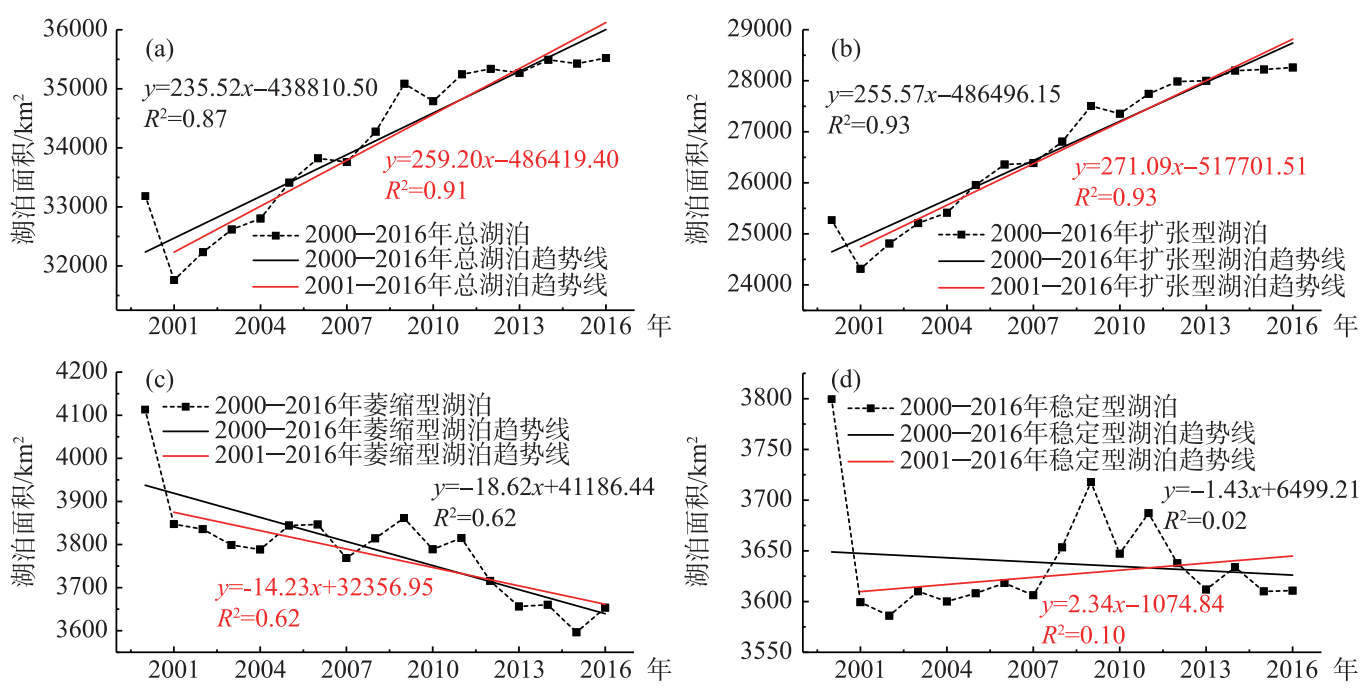

图 32000 年以来青藏高原湖泊面积变化趋势

（a-138 个湖泊; b-扩张型湖泊; c-萎缩型湖泊; d-稳定型湖泊）

Fig. 3 Trends of lake area changes in the Tibetan Plateau since 2000

( a-138 lakes; b-expanded lakes; c-atrophic lakes; d-stable lakes)

3.3.2 按主要补给来源分类 青藏高原湖泊按补给来源可分 为冰雪融水补给、冰雪融水与湖面降水补给、地表径流补给、 河流补给、湖泊补给和泉水补给共 7 类 $^{[48-49]}$, 本文进一步归 纳为冰雪融水补给、地表径流补给和河流补给 3 类.

2000 年以来青藏高原以冰雪融水为主要补给方式的湖 泊 ${ }^{[56-57]}$ 年均面积约 $11837.37 \mathrm{~km}^{2}$, 总体呈现扩张趋势 $(\mathrm{a}=$ $82.32 \mathrm{~km}^{2} / \mathrm{a}, R^{2}=0.87$ ) (图 5a), 其中扩张型湖泊占 $59.52 \%$;
表 2 湖泊面积变化分类

Tab.2 Classification of lake area change types

\begin{tabular}{cc}
\hline 湖泊面积变化类型 & $\mathrm{a}$ 值 \\
\hline 萎缩型 & $\mathrm{a}<-0.17$ \\
稳定型 & $|\mathrm{a}| \leqslant 0.17$ \\
扩张型 & $\mathrm{a}>0.17$ \\
\hline
\end{tabular}
2001 年后湖泊面积表现为显著线性增长趋势. 以地表径流为主要补给方式的湖泊年均面积为 $3790.70 \mathrm{~km}^{2}$, 整体呈扩张趋势 $\left(\mathrm{a}=14.29 \mathrm{~km}^{2} / \mathrm{a}, R^{2}=0.47\right.$ ) (图 $5 \mathrm{~b}$ ), 扩张型湖泊占 $72.00 \%$; 在 2012 年之前, 湖泊面积以波 动方式快速增长, 近几年湖泊面积呈萎缩趋势. 以河流为主要补给方式的湖泊年均面积约为 $11287.55 \mathrm{~km}^{2}$, 总体呈扩张趋势 $\left(\mathrm{a}=82.14 \mathrm{~km}^{2} / \mathrm{a}, R^{2}=0.91\right.$ ) (图 5c) , 其中扩张型湖泊占 $71.43 \%$. 整体而言, 2001 年后 3 种 补给方式的湖泊面积扩张趋势显著.
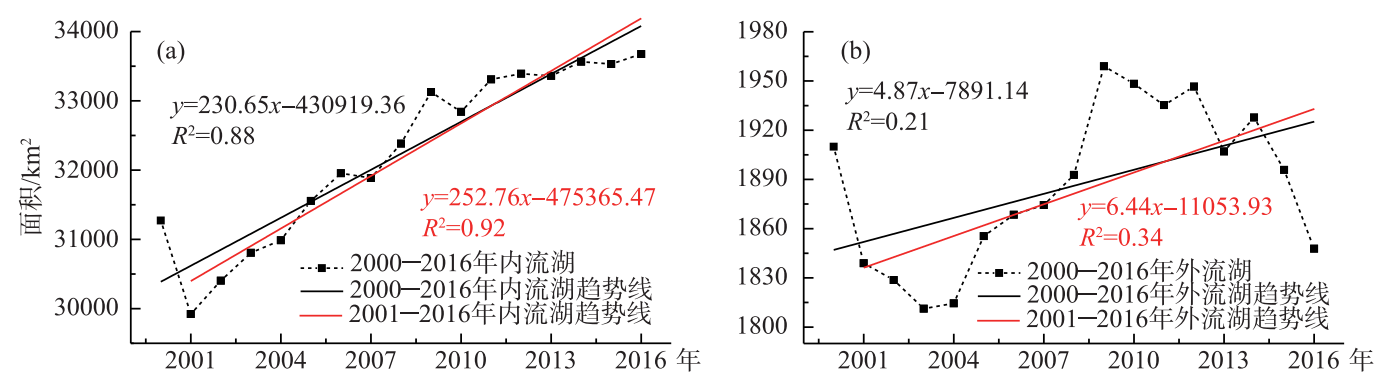

图 42000 年以来青藏高原内流湖 ( a ) 和外流湖 (b) 面积变化趋势

Fig.4 Trends of lake area changes of inflow lakes(a) and outflow lakes (b) in the Tibetan Plateau since 2000 色林错 (图 6a), 目前已成为西藏面积 


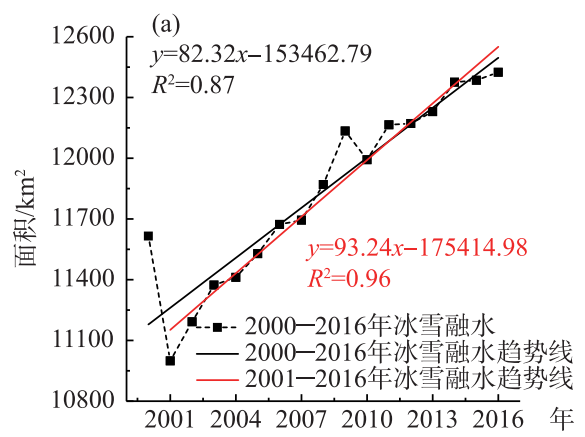

(b)
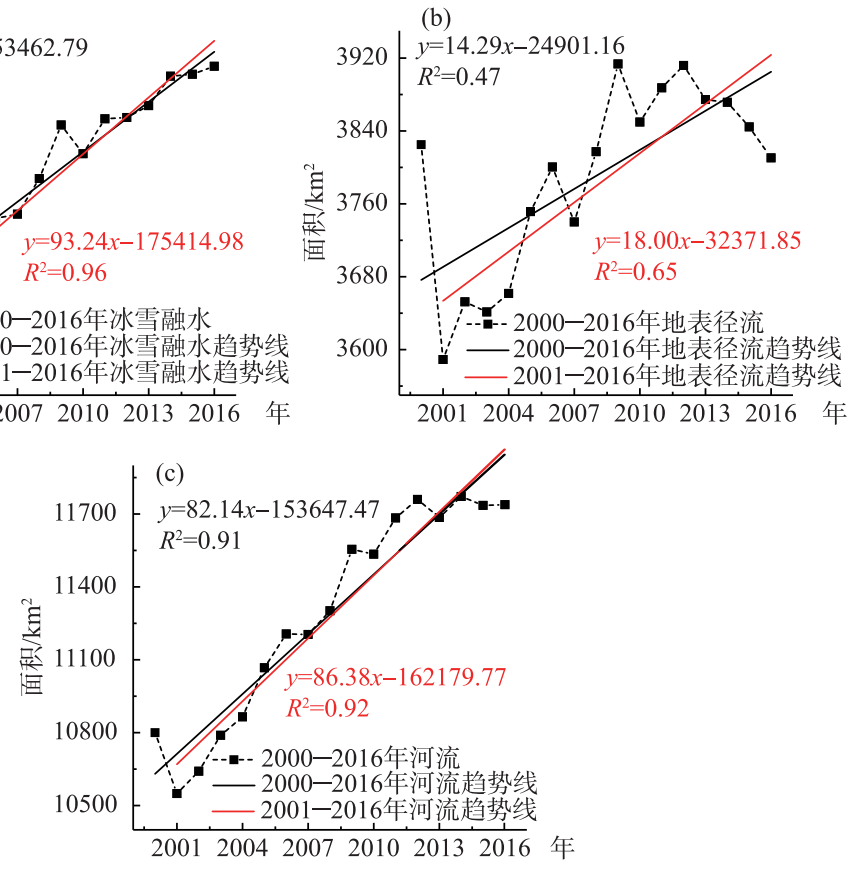

图 52000 年以来青藏高原 3 种补给方式湖泊面积变化趋势

（a-冰雪融水补给; b-地表径流补给; $c$-河流补给）

Fig.5 Trends of lake area changes of the three supply modes in the Tibetan Plateau since 2000

( a-glacier melt water; b-surface runoff; c-river)

最大的湖泊. 色林错面积呈显著扩张趋势, 2000-2009 年色林错面积加速增长, 到 2010 年稍有减少, 之后湖 泊面积呈现波动变化. 截止到 2016 年, 不包括雅个冬错的色林错湖泊面积已达到 $2244.73 \mathrm{~km}^{2}$. 相关研究认 为 $^{[7-8,58]}$, 气温上升导致冰雪融水增加是湖泊上涨的主要原因, 其次与降水量的增加和蒸发量的减少、冻土退 化等也存在很大关系. 2004 年色林错南部湖面同雅个冬错联通, 本次研究提取湖泊时将色林错与雅个冬错 的面积分开计算. 据统计雅个冬错在 2004 年之前从面积较稳定的 $50 \mathrm{~km}^{2}$ 突增到 $88.22 \mathrm{~km}^{2}$, 若将色林错和雅 个冬错合并分析,色林错的扩张趋势将更显著.
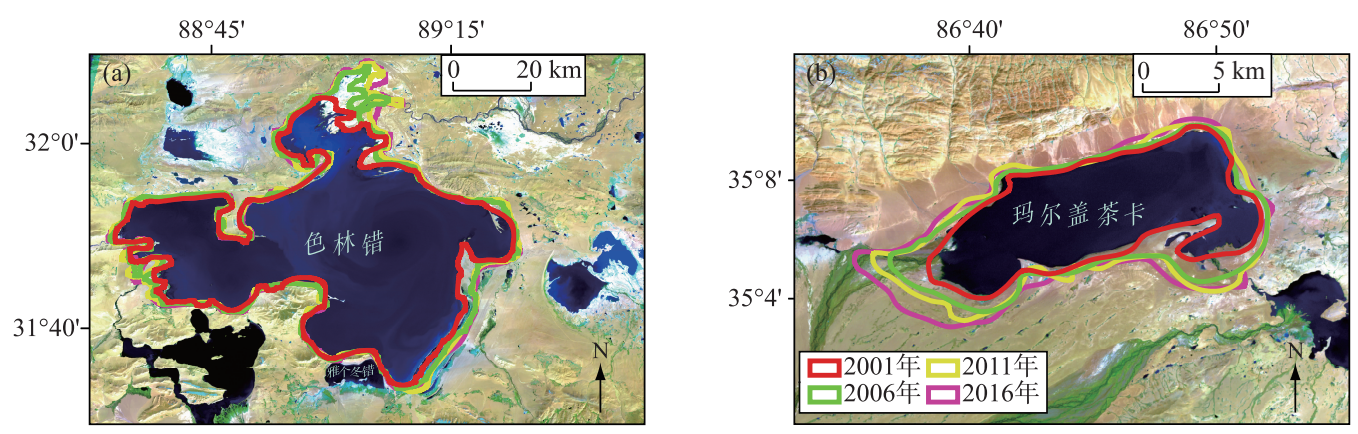

图 62000 年以来色林错 (a) 和玛尔盖茶卡 (b) 湖泊面积变化

Fig. 6 Changes of lake area in Selin Co(a) and Margai Caka(b) since 2000

3.3.3 按湖泊矿化度分类 青藏高原湖泊据其湖水矿化度可以分为盐湖、咸水湖和淡水湖 ${ }^{[15,48-49,59]}$ 三类 (图 $7)$. 根据《中国湖泊分布地图集》 ${ }^{[48]}$ 、《中国湖泊志》 ${ }^{[49]}$ 、《青藏高原盐湖》 ${ }^{[50]}$ 、中国盐湖志》 ${ }^{[51]}$ 等资料确定 
了 137 个湖泊的矿化度 ( “Noname_2” 的湖水矿化度不明, 未在统计之列), 其中以塔若错、鄂陵湖和格仁错 等为代表的淡水湖 23 个; 以色林错、青海湖、纳木错、扎日南木错等为代表的咸水湖 63 个; 以玛尔盖茶卡、班 戈错、鄂雅错等湖泊为代表的盐湖 51 个. 不同矿化度湖泊面积变化统计结果表明, 盐湖中扩张型占 $80.40 \%$, 稳定型占 $11.76 \%$,萎缩型占 $7.84 \%$; 咸水湖中扩张型占 $71.43 \%$, 稳定型占 $17.46 \%$, 萎缩型占 $11.11 \%$; 扩张型 淡水湖 $30.43 \%$, 稳定型淡水湖 $43.48 \%$, 萎缩型淡水湖 $26.09 \%$. 盐湖与咸水湖主要以扩张型为主, 淡水湖以 稳定型为主.

其中, 湖水矿化度为 $323.55 \mathrm{~g} / \mathrm{L}^{[51]}$ 的玛尔盖茶卡 (图 $6 \mathrm{~b}$ ), 属重要的含钾、锂、硼盐湖. 结果显示, 玛尔盖 茶卡面积由 2000 年的 $102.31 \mathrm{~km}^{2}$ 持续增长到 2009 年的 $149.17 \mathrm{~km}^{2} .2010$ 年湖泊面积稍有减少, 之后呈现平 稳扩张趋势, 到 2016 年湖泊面积已达 $164.76 \mathrm{~km}^{2}$. 青藏高原发育大量现代湖表卤水型特种盐湖, 由气候变化 引起湖泊面积扩张、湖水矿化度降低、盐湖卤水淡化, 由此导致盐湖资源开发成本增加甚至失去开发利用的 价值. 建议有关部门针对国家急需矿种盐湖资源 (如锂等) 作好“抢救式”开发部署.

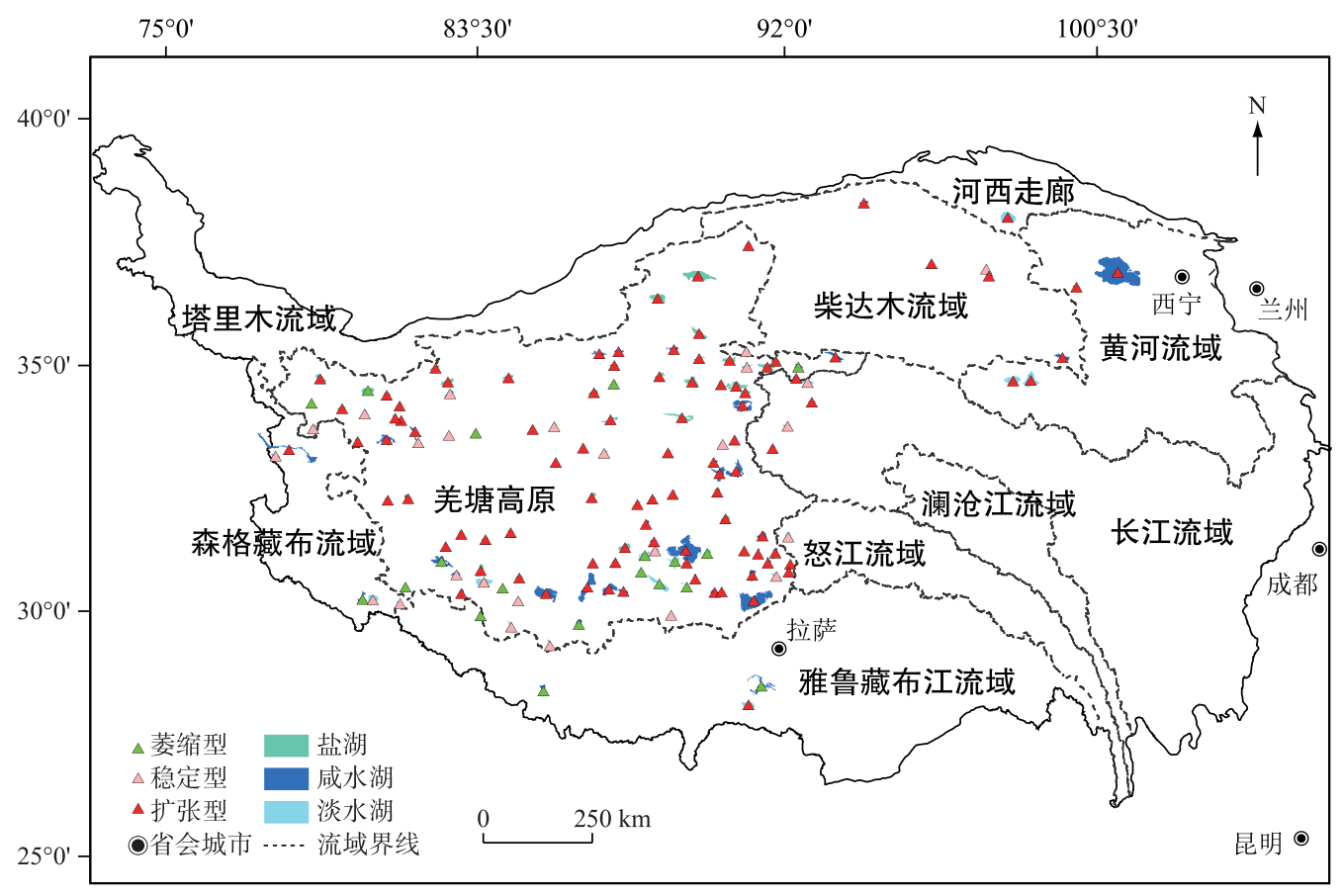

图 7 青藏高原面积大于 $50 \mathrm{~km}^{2}$ 湖泊矿化度分类与湖泊面积变化分类

Fig.7 Classifications of lake salinity and area changes in the Tibetan Plateau with an area of more than $50 \mathrm{~km}^{2}$

\section{4 湖泊面积变化对气候要素的响应}

3.4.1 青藏高原气候变化背景 相关研究认为, 青藏高原气候向暖湿化方向发展 ${ }^{[13,60]}$, 这与气温升高、降水 量增加和蒸发量减少有关 ${ }^{[61-65]}$. 青藏高原湖泊的整体扩张趋势受气候变化驱动明显 ${ }^{[5,7,13,18-22,66]}$, 湖泊面积变 化对气候变化具有一定的时滞效应 ${ }^{[8]}$, 为把握青藏高原长时间序列气候变化背景, 选取中国区域高时空分 辨率地面气象要素驱动数据集中 1980-2015 年 7-9 月青藏高原月平均气温和累计降水量数据, 并分析近 36 年来青藏高原气候变化趋势. 结果显示, 7-9 月平均气温 (图 8a) 呈波动增加趋势, 速率为 $0.34^{\circ} \mathrm{C} / 10 \mathrm{a}$; 7-9 月累计降水量 (图 8b) 呈明显增加趋势, 增加速率为 $20.26 \mathrm{~mm} / 10$ a. 其中, 2000 年 7-9 月平均气温比 1999 年和 2001 年同期低,气温低导致冰雪融水和湖面蒸发量减少, 7-9 月累计降水量又比 1999 年和 2001 年同期多,这些综合因素可能是 2000 年湖泊面积整体较大的原因之一( 图 3、图 4、图 5).

同时, 采用线性趋势分析法 ${ }^{[67-68]}$ 得到高原区内 1980-2015 年 7-9 月平均气温和累计降水量的变化趋 势, 其中, 线性趋势斜率 $>0$ 表明变化趋势增加, 反之则减少. 

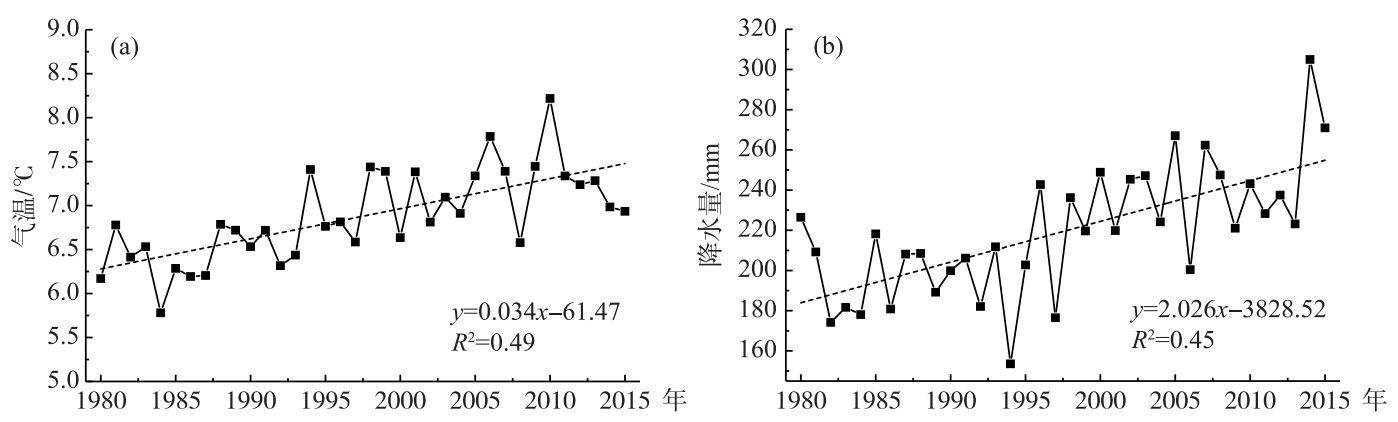

图 8 1980-2015 年 7-9 月青藏高原平均气温(a)和累计降水量 (b) 的年际变化

Fig. 8 The annual variations of the mean air temperature(a) and accumulative precipitation( $b$ ) from July to September in the Tibetan Plateau during 1980-2015

近 36 年来, 青藏高原 7-9 月气温整体增温趋势明显 (图 9a), 自美塘高原中部到雅鲁藏布江流域、长江 流域、黄河流域和河西走廊增温趋势逐渐减弱,森格藏布流域西部增温趋势明显, 塔里木流域南部和芫塘高 原西部气温呈递减趋势. 降水量变化趋势空间差异明显 (图 9b), 高原腹地即面积大于 $50 \mathrm{~km}^{2}$ 的湖泊集中分 布区降水量以显著增加为主, 长江流域、澜沧江流域、怒江流域和黄河流域东南部降水量以微弱减少为主, 其中降水量减少区面积大于 $50 \mathrm{~km}^{2}$ 的湖泊分布较少.
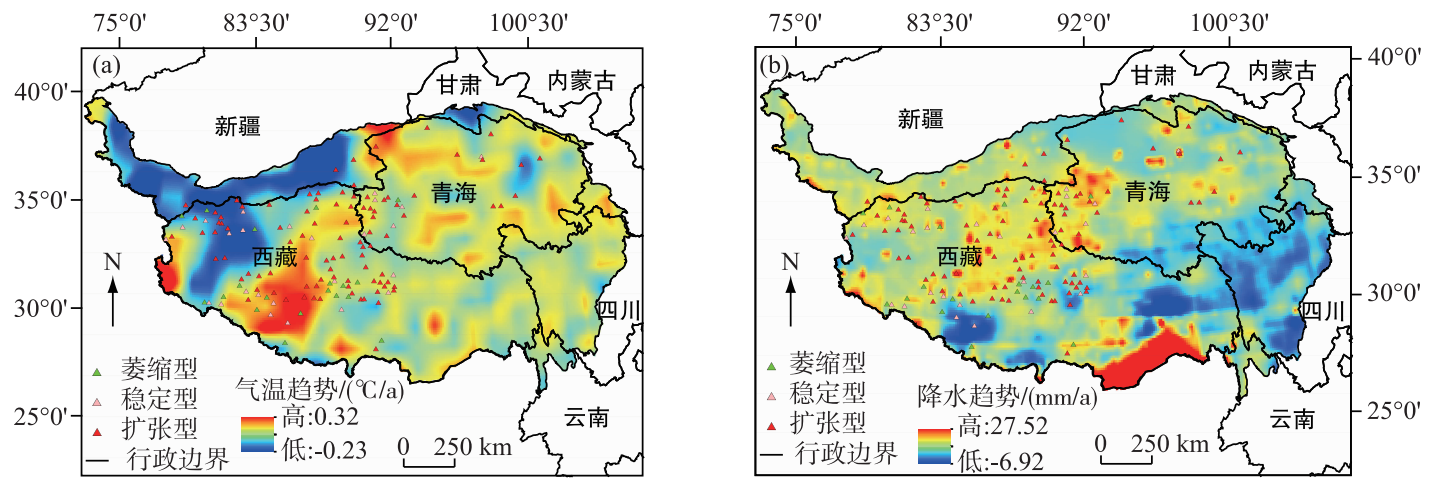

图 9 1980-2015 年青藏高原 7-9 月平均气温(a) 与累计降水量 (b) 变化趋势

Fig.9 Trends of the mean air temperature(a) and accumulative precipitation( b ) from July to September in the Tibetan Plateau during 1980-2015

3.4.2 气候要素趋势分区响应 为进一步分析湖泊面积变化与区域气候之间的关系,依据中国区域高时空分 辨率地面气象要素驱动数据集计算的青藏高原 1980-2015 年 7-9 月平均气温和 7-9 月累计降水量变化 趋势, 将青藏高原划分为 5 个气候变化趋势区 (表 3 和图 10), 统计了各区的湖泊和冰川面积 (表 4).

I 区位于西藏中、东部和青海西部, 横跨美塘高原中部、长江流域和柴达木流域西部; 该区平均气温和 降水量呈增加趋势, 特别是降水量增加趋势明显; 区内面积大于 $50 \mathrm{~km}^{2}$ 的湖泊数量最多, 扩张型湖泊占 $78.18 \%$, 稳定型湖泊占 $16.36 \%$, 萎缩型湖泊占 $5.46 \%$; 区内冰川覆盖率为 $1.60 \%$, 湖泊主要由芫塘高原发育 的冰川融水补给. II 区主要位于西藏南部, 青海中、东部,包括柴达木流域和羌塘高原南部区域; 区内平均气 温和累计降水量呈增加趋势, 该区扩张型湖泊占 $60.78 \%$, 稳定型湖泊占 $19.61 \%$, 萎缩型湖泊占 $19.61 \%$; 区 内冰川覆盖率为 $0.86 \%$, 湖泊主要由祁连山、昆仑山和冈底斯山的部分冰川融水补给. III 区位于青海省南 部、四川省西北部和西藏南部, 主体位于三江流域、雅鲁藏布江流域西部和芫塘高原南部部分流域; 区内平 均气温呈增加趋势, 累计降水量呈微弱减少趋势, 该区 6 个面积大于 $50 \mathrm{~km}^{2}$ 的湖泊中扩张型湖泊占 $50.00 \%$, 
稳定型湖泊占 $33.33 \%$,萎缩型湖泊占 $16.67 \%$; 区内冰川覆盖率为 $1.59 \%$, 湖泊主要由横断山、念青唐古拉 山、唐古拉山和喜马拉雅山的部分冰川融水补给. IV 区位于新疆南部和西藏北部部分地区,包括塔里木流域 和芫塘高原部分区域; 区内气温呈微弱降低趋势, 降水量增加趋势明显, 该区扩张型湖泊占 $58.83 \%$, 稳定型 湖泊占 $29.41 \%$, 萎缩型湖泊占 $11.76 \%$; 区内冰川覆盖率为 $8.88 \%$, 湖泊主要由喀喇昆仑山和昆仑山的冰川 融水补给. V 区位于新疆南部地区和青海东部部分地区,包括芫塘高原西北部、塔里木流域南部和黄河流域 西部; 区内气温呈降低趋势, 累计降水量呈增加趋势, 该区扩张型湖泊占 $66.67 \%$, 稳定型湖泊占 $22.22 \%$, 萎 缩型湖泊占 $11.11 \%$; 区内冰川覆盖率为 $2.86 \%$, 湖泊主要由昆仑山和冈底斯山的部分冰川融水补给.

表 3 青藏高原气候变化趋势区湖泊统计*

Tab.3 Lakes statistics of climate change trends zone in the Tibetan Plateau

\begin{tabular}{cccccc}
\hline 分区 & 气温趋势 $/\left({ }^{\circ} \mathrm{C} / \mathrm{a}\right)$ & 降水量趋势 $/(\mathrm{mm} / \mathrm{a})$ & 扩张型比例 $/ \%$ & 萎缩型比例 $/ \%$ & 稳定型比例 $/ \%$ \\
\hline I 区 & $+\left(0 \leqslant \mathrm{a}_{\mathrm{T}} \leqslant 0.32\right)$ & $++\left(3<\mathrm{a}_{\mathrm{P}} \leqslant 27.52\right)$ & 78.18 & 5.46 & 16.36 \\
II 区 & $+\left(0 \leqslant \mathrm{a}_{\mathrm{T}} \leqslant 0.32\right)$ & $+\left(0<\mathrm{a}_{\mathrm{P}} \leqslant 3\right)$ & 60.78 & 19.61 & 19.61 \\
III 区 & $+\left(0 \leqslant \mathrm{a}_{\mathrm{T}} \leqslant 0.32\right)$ & $-\left(-6.92 \leqslant \mathrm{a}_{\mathrm{P}} \leqslant 0\right)$ & 50.00 & 16.67 & 33.33 \\
IV 区 & $-\left(-0.23 \leqslant \mathrm{a}_{\mathrm{T}}<0\right)$ & $++\left(3<\mathrm{a}_{\mathrm{P}} \leqslant 27.52\right)$ & 58.83 & 11.76 & 29.41 \\
V 区 & $-\left(-0.23 \leqslant \mathrm{a}_{\mathrm{T}}<0\right)$ & $+\left(0<\mathrm{a}_{\mathrm{P}} \leqslant 3\right)$ & 66.67 & 11.11 & 22.22 \\
\hline
\end{tabular}

$*$ 本文将气温趋势分为增加趋势 $(+)$ 和减少趋势 $(-)$ 两级, 将累计降水量趋势分为微弱增加趋势 $(+)$ 、增加趋势 $(++)$ 和 减少趋势 $(-)$ 三级; 由于实际分区时气温减少趋势 $(-)$ 和降水减少趋势 $(-)$ 同时满足的区域极小 (可忽略不计) 且无湖泊 分布,制图时与其他区域合并处理.

表 4 青藏高原气候变化趋势区湖泊、冰川面积统计*

Tab.4 Lakes and glaciers area statistics of climate change trends zone in the Tibetan Plateau

\begin{tabular}{|c|c|c|c|c|c|c|c|}
\hline 分区 & $\begin{array}{c}\text { 区域面积/ } \\
\left(\times 10^{4} \mathrm{~km}^{2}\right)\end{array}$ & $\begin{array}{c}\text { 湖泊总面积/ } \\
\mathrm{km}^{2}\end{array}$ & $\begin{array}{c}\text { 冰川面积/ } \\
\mathrm{km}^{2}\end{array}$ & $\begin{array}{c}\text { 冰川覆盖率/ } \\
\%\end{array}$ & $\begin{array}{c}\text { 湖泊数量/ } \\
\text { 个 }\end{array}$ & $\begin{array}{c}\text { 冰雪融水补给 } \\
\text { 湖泊数量/个 }\end{array}$ & $\begin{array}{c}\text { 冰雪融水补给 } \\
\text { 湖泊比例 } / \%\end{array}$ \\
\hline I 区 & 46.80 & 10820.66 & 7474.35 & 1.60 & 55 & 25 & 45.45 \\
\hline II 区 & 122.70 & 16680.37 & 10492.89 & 0.86 & 51 & 17 & 33.33 \\
\hline III 区 & 46.20 & 2701.64 & 7362.56 & 1.59 & 6 & 2 & 33.33 \\
\hline IV 区 & 6.80 & 2304.60 & 6039.04 & 8.88 & 17 & 8 & 47.06 \\
\hline V 区 & 39.00 & 1612.36 & 11154.90 & 2.86 & 9 & 4 & 44.44 \\
\hline
\end{tabular}

* 湖泊总面积为研究时间段内的平均值.

对比结果显示 (图 10), 气温、降水增加趋势越显著, 湖泊扩张趋势越明显. I 区暖湿化程度最明显 $\left(\mathrm{a}_{\mathrm{T}}=\right.$ $\left.0.55^{\circ} \mathrm{C} / 10 \mathrm{a}, \mathrm{a}_{\mathrm{p}}=53.37 \mathrm{~mm} / 10 \mathrm{a}\right)$, 其次是 II 区 $\left(\mathrm{a}_{\mathrm{T}}=0.54^{\circ} \mathrm{C} / 10 \mathrm{a}, \mathrm{a}_{\mathrm{p}}=16.92 \mathrm{~mm} / 10 \mathrm{a}\right)$, III 区呈现暖干化 $\left(\mathrm{a}_{\mathrm{T}}=\right.$ $\left.0.54^{\circ} \mathrm{C} / 10 \mathrm{a}, \mathrm{a}_{\mathrm{p}}=-12.44 \mathrm{~mm} / 10 \mathrm{a}\right)$, IV 区 $\left(\mathrm{a}_{\mathrm{T}}=-0.71^{\circ} \mathrm{C} / 10 \mathrm{a}, \mathrm{a}_{\mathrm{p}}=37.66 \mathrm{~mm} / 10 \mathrm{a}\right)$ 和 $\mathrm{V} 区\left(\mathrm{a}_{\mathrm{T}}=-0.53^{\circ} \mathrm{C} / 10 \mathrm{a}, \mathrm{a}_{\mathrm{p}}=\right.$ $24.82 \mathrm{~mm} / 10 \mathrm{a})$ 的气候呈现冷湿化. 相应地, I 区湖泊扩张程度最剧烈, 其次是 V 区、 II 区和 IV 区, III 区的湖 泊面积变化相对不大. 近几十年来受全球气候变暖影响, 除西昆仑峰区和喀喇昆仑山地区冰川较稳定 外 $^{[69-70]}$, 青藏高原冰川普遍呈持续退缩的趋势 ${ }^{[71-73]}$. I 区气温呈增加趋势, 降水量增加趋势显著, 区内㒸塘 高原冰川退缩 ${ }^{[74]}$, 可见气温升高导致的冰雪融水补给和降水补给导致了湖泊扩张显著. II 区气温和降水量 都呈增加趋势, 湖泊集中区的祁连山冰川年均冰量损失 $(534.2 \pm 399.5) \times 10^{6} \mathrm{~m}^{3[75]}$, 同时㒸塘高原南部冰川 整体也呈退缩趋势 ${ }^{[76]}$. 冰雪融水增加和降水量的共同作用使湖泊扩张率为 $60.78 \%$. III 区气温呈升高趋势, 降水量呈减少趋势, 湖泊集中区的冈底斯山冰川 ${ }^{[77]}$ 和念青唐古拉山东段冰川 ${ }^{[78]}$ 呈退缩趋势, 而湖泊扩张率 为 $50.00 \%$, 气温升高导致的冰川加剧退缩是导致 III 区湖泊扩张的主要原因. IV 区气温呈降低趋势, 降水量 呈明显增加趋势, 该区西昆仑山冰川退缩幅度较小 $(0.65 \%)$, 面积减少 $16.83 \mathrm{~km}^{2[69]}$, 而该区湖泊扩张率为 $58.83 \%$, 降水量的增加是 IV 区湖泊扩张的主导因素. V 区气温呈下降趋势, 而降水量呈增加趋势, 在区内冈 底斯山脉、昆仑山脉和芫塘高原冰川退缩和降水量增加的共同作用下, 湖泊整体扩张率为 $66.67 \%$, 其中降水 量的增加是 $\mathrm{V}$ 区湖泊扩张的主导因子. 对比冰川覆盖率接近的 I 区和 III 区, I 区受冰雪融水补给的湖泊占 


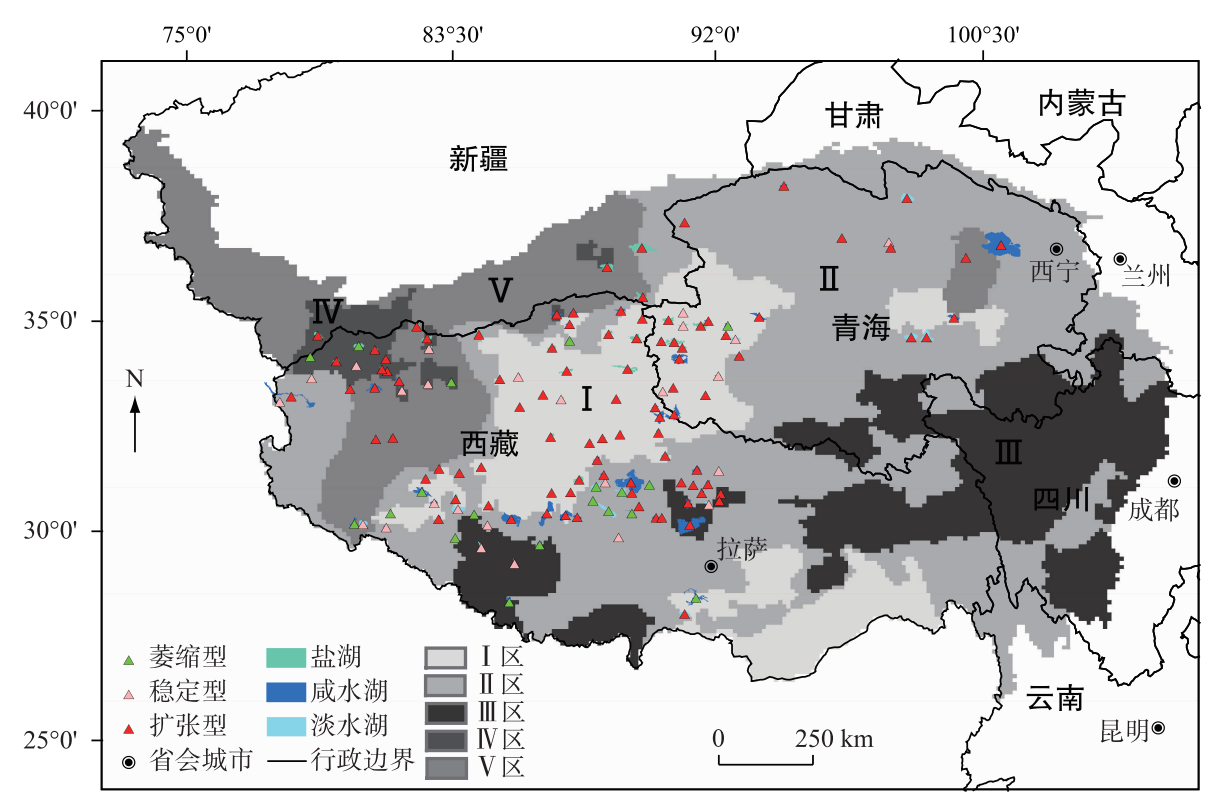

图 10 青藏高原气候要素趋势分区

Fig.10 Zones of climate factors change trend in the Tibetan Plateau

比、降水量趋势都大于 III 区，I 区湖泊扩张程度大于 III 区; II 区气温升高趋势强于 V 区, 但 V 区冰川覆盖率、 冰雪融水补给湖泊比例高于 II 区, V 区湖泊扩张程度大于 II 区; I 区冰川覆盖率、冰雪融水补给湖泊比例小 于IV 区, 但 I 区气温升高趋势强于IV 区, I 区湖泊扩张程度大于IV 区. 可见,受不同程度气温、降水和冰雪融 水补给影响, 不同气候趋势分区下的湖泊面积变化存在明显的差异. 前人研究结果表明,近 40 年青藏高原 湖泊面积在气候暖湿化的影响下, 整体上以扩张趋势为主, 特别是 2000 年以来, 高原湖泊面积整体呈加速 扩张趋势 ${ }^{[5,7-8,13,15,18-22]}$. 其中, 大部分研究认为, 青藏高原湖泊主要受气温升高导致冰雪融化增加致使面积扩 张趋势显著 ${ }^{[5,820-22]}$; 也有部分研究基于有限的青藏高原典型内流湖泊分析认为, 降水量的变化是导致湖泊 面积变化的主要驱动因子 ${ }^{[18-19]}$. 本文基于青藏高原面积大于 $50 \mathrm{~km}^{2}$ 的湖泊,通过对比湖泊的主要补给方式 和气候变化趋势分区认为, 在受人为因素影响较小的青藏高原地区, I 区、II 区和 III 区升温引起的冰雪融水 补给对湖泊面积变化的影响显著, 加之降水量的增加, 湖泊扩张率增加明显; IV 区和 V 区湖泊面积变化主要 受降水量增加影响显著.

\section{4 结论}

基于 MOD09A1 数据、DEM 数据和气象数据, 提取 2000-2016 年青藏高原湖泊面积信息, 并从内外流分 区、湖泊主要补给来源和湖水矿化度分析其变化特征, 首次基于气候要素变化趋势分区分析湖泊面积变化 与气候要素的关系, 主要结论如下:

1) 青藏高原连续 17 年面积大于 $50 \mathrm{~km}^{2}$ 的 138 个湖泊中, 扩张型湖泊占 $67.39 \%$, 萎缩型湖泊占 $12.32 \%$, 稳定型湖泊占 $20.29 \%$, 扩张型和萎缩型湖泊面积线性趋势显著. 湖泊面积总体呈显著扩张趋势, 17 年间总 面积增加 $2340.67 \mathrm{~km}^{2}$, 增长速率为 $235.52 \mathrm{~km}^{2} / \mathrm{a}$. 其中, 色林错、阿雅格库、青海湖等湖泊面积呈显著扩张趋 势; 霍鲁诺尔、羊卓雍错等湖泊面积呈显著萎缩趋势; 泽错、拜惹布错等湖泊面积保持基本稳定.

2) 内流湖扩张趋势显著, 外流湖扩张趋势较明显; 以冰雪融水为主要补给来源的湖泊整体扩张趋势明 显, 以地表径流和河流补给为主要补给源的湖泊也呈扩张趋势; 盐湖和咸水湖以扩张为主, 淡水湖的扩张、 萎缩和稳定 3 种类型较均衡.

$3)$ 近 36 年青藏高原气候向暖湿化方向发展, 表现为 7-9 月平均气温增长速率为 $0.34^{\circ} \mathrm{C} / 10 \mathrm{a}$, 累计降水 
量增长速率为 $20.26 \mathrm{~mm} / 10 \mathrm{a}$. 区域气候要素变化趋势存在明显的差异, 导致湖泊面积变化具有区域差异性.

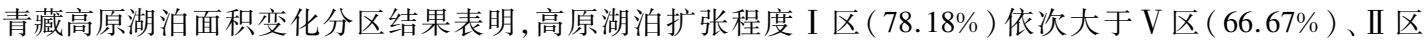
$(60.78 \%) 、 I V 区(58.83 \%)$ 和 III 区 $(50.00 \%)$.

4) 不同补给来源的湖泊对气候变化的响应程度不同,气温主要影响以冰雪融水为主要补给来源的湖 泊, 降水量主要影响以降水和地表径流为主要补给来源的湖泊. 升温引起的冰雪融水补给对 I 区、 II 区和 III 区湖泊面积扩张的影响显著, 加之降水量的增加, 湖泊扩张率增加明显. IV 区和 V 区湖泊面积扩张主要受降 水量增加影响显著.

\section{5 参考文献}

[ 1 ] Qiu J. China: The third pole. Nature, 2008, 454(7203) : 393-396.

[ 2 ] Yao T, Thompson LG, Mosbrugger V et al. Third Pole Environment (TPE). Environmental Development, 2012, 3(1): $52-64$.

[ 3 ] Li ZG. Glaciers and lakes changes on the Qinghai-Tibet Plateau under climate change in the past 50 years. Journal of Natural Resources, 2012, 27 (8): 1431-1443. [ 李治国. 近 $50 \mathrm{a}$ 气候变化背景下青藏高原冰川和湖泊变化. 自然资源学 报, 2012, 27(8): 1431-1443.]

[ 4 ] Zheng MP, Liu XF. Hydrochemistry and minerals assemblages of salt lakes in the Qinghai-Tibet Plateau, China. Acta Geologica Sinica, 2010, 84(11): 1585-1600. [郑绵平, 刘喜方. 青藏高原盐湖水化学及其矿物组合特征. 地质学报, $2010,84(11): 1585-1600$.

[ 5 ] Yan LJ, Zheng MP, Wei LJ. Change of the lakes in Tibetan Plateau and its response to climate in the past forty years. Earth Science Frontiers, 2016, 23(4): 310-323. [间立娟, 郑绵平, 魏乐军. 近 40 年来青藏高原湖泊变迁及其对气 候变化的响应. 地学前缘, 2016, 23(4): 310-323.]

[ 6 ] Yao TD, Zhang YS, Pu JC et al. Twenty-year observations of glacier, hydrology and meteorology at the Tanggula Pass of the Tibetan Plateau: significance and achievements. Journal of Glaciology and Geocryology, 2010, 32(6) : 1152-1161. [姚檀栋, 张寅生, 蒲健辰等. 青藏高原唐古拉山口冰川、水文和气候学观测 20a: 意义与贡献. 冰川冻土, 2010, 32(6): 1152-1161.]

[ 7 ] Yi GH, Deng W, Li AN et al. Response of lakes to climate change in Xainza Basin Tibetan Plateau using multi-mission satellite data from 1976 to 2008. Journal of Mountain Science, 2015, 12(3): 604-613.

[ 8 ] Yi GH, Zhang TB. Delayed response of lake area change to climate change in Siling Co lake, Tibetan Plateau, from 2003 to 2013. International Journal of Environmental Research \& Public Health, 2015, 12(11): 13886-900.

[ 9 ] Crétaux JF, Jelinski W, Calmant S et al. SOLS: A lake database to monitor in the Near Real Time water level and storage variations from remote sensing data. Advances in Space Research, 2011, 47 (9) : 1497-1507. DOI: 10.1016/j.asr.2011. 01.004.

[10] Zhang G, Xie H, Kang S et al. Monitoring lake level changes on the Tibetan Plateau using ICESat altimetry data (20032009). Remote Sensing of Environment, 2011, 115(7) : 1733-1742. DOI: 10.1016/j.rse.2011.03.005.

[11] Liu J, Wang S, Yu S et al. Climate warming and growth of high-elevation inland lakes on the Tibetan Plateau. Global \& Planetary Change, 2009, 67(3/4) : 209-217.

[12] Qiao C, Luo JC, Sheng YW et al. Analysis on lake change since ancient and modern ages using remote sensing in Dagze Co, Tibet Plateau. J Lake Sci, 2010, 22(1) : 98-102. DOI:10.18307/2010.0114. [乔程, 骆剑承, 盛永伟等. 青藏高 原湖泊古今变化的遥感分析一—达则错为例. 湖泊科学, 2010, 22(1): 98-102.]

[13] Dong SY, Xue X, You QG et al. Remote sensing monitoring of the lake area changes in the Qinghai-Tibet Plateau in recent 40 years. J Lake Sci, 2014, 26 (4) : 535-544. DOI: 10.18307/2014.0407. [董斯扬, 薛涃, 尤全刚等. 近 40 年青藏高 原湖泊面积变化遥感分析. 湖泊科学, 2014, 26(4) : 535-544.]

[14] Zhang G, Yao T, Xie H et al. Lakes' state and abundance across the Tibetan Plateau. Science Bulletin, 2014, 59(24): 3010-3021. DOI: 10.1007/s11434-014-0258-x.

[15] Wan W, Long D, Hong Y et al. A lake data set for the Tibetan Plateau from the 1960s, 2005, and 2014. Scientific Data, 2016, 3(3).

[16] Crétaux JF, Abarca-Del-Río R, Bergé-Nguyen M et al. Lake volume monitoring from space. Surveys in Geophysics, 2016, 
37(2) : 1-37. DOI: 10.1007/s10712-016-9362-6.

[17] Zhang G, Yao T, Shum CK et al. Lake volume and groundwater storage variations in Tibetan Plateau's endorheic basin. Geophysical Research Letters, 2017, 44: 5550-5560. DOI: 10.1002/2017GL073773.

[18] Lei Y, Yang K, Wang B et al. Response of inland lake dynamics over the Tibetan Plateau to climate change. Climatic Change, 2014, 125(2) : 281-290.

[19] Li B, Zhang J, Yu Z et al. Climate change driven water budget dynamics of a Tibetan inland lake. Global \& Planetary Change, 2017, 150: 70-80.

[20] Wan W, Xiao P, Feng X et al. Monitoring lake changes of Qinghai-Tibetan Plateau over the past 30 years using satellite remote sensing data. Science Bulletin, 2014, 59(10): 1021-1035.

[21] Wang X, Gong P, Zhao Y et al. Water-level changes in China's large lakes determined from ICESat/GLAS data. Remote Sensing of Environment, 2013, 132:131-144.

[22] Jiang L, Nielsen K, Andersen OB et al. Monitoring recent lake level variations on the Tibetan Plateau using CryoSat-2 SARIn mode data. Journal of Hydrology, 2017, 544:109-124.

[23] Huang WD, Liao JJ, Shen GZ. Lake change in past 40 years in the southern Nagqu district of Tibet and analysis of its driving forces. Remote Sensing for Land \& Resources, 2012, 24(3): 122-128. [黄卫东, 廖静娟, 沈国状. 近 40 年西藏那 曲南部湖泊变化及其成因探讨. 国土资源遥感, 2012, 24(3) : 122-128.]

[24] Song CQ, Huang B, Ke LH. Modeling and analysis of lake water storage changes on the Tibetan Plateau using multi-mission satellite data. Remote Sensing of Environment, 2013, 135: 25-35.

[25] Zhu LP, Xie MP, Wu YH. Quantitative analysis of lake area variations and the influence factors from 1971 to 2004 in the Nam Co Basin of the Tibetan Plateau. Chinese Science Bulletin, 2010, 55(18) : 1789-1798. DOI: 10.1007/s11434-0100015-8. [ 朱立平, 谢曼平, 吴艳红. 西藏纳木错 1971-2004 年湖泊面积变化及其原因的定量分析. 科学通报, $2010, \mathbf{5 5}(18)$ : 1789-1798. ]

[26] Bian D, Bian BCR, La B et al. The response of water level of Selin Co to climate change during 1975-2008. Acta Geographica Sinica, 2010, 65(3):313-319. [边多, 边巴次仁, 拉巴等. 1975-2008 年西藏色林错湖面变化对气候变 化的响应. 地理学报, 2010, 65(3): 313-319.]

[27] McFeeters SK. The use of the Normalized Difference Water Index (NDWI) in the delineation of open water features. International Journal of Remote Sensing, 1996, 17(7) : 1425-1432.

[28 ] Landmann T, Schramm M, Colditz RR et al. Wide area wetland mapping in semi-arid Africa using 250-meter MODIS metrics and topographic variables. Remote Sensing, 2010, 2(7) : 1751-1766.

[29] Liu CZ, Shi JC, Gao S et al. The study on extracting of water body from MODIS image using an improved linear mixture model. Remote Sensing Information, 2010，(1) :84-88. [刘晨洲, 施建成, 高帅等. 基于改进混合像元方法的 MODIS 影像水体提取研究. 遥感信息, 2010, (1):84-88.]

[30] Liao CH, Liu XH. An effectiveness comparison between water body indices based on MODIS data. Remote Sensing for Land \& Resources, 2008, 20(4) : 22-26. [廖程浩, 刘雪华. MODIS 数据水体识别指数的识别效果比较分析. 国土资源遥 感, $2008,20(4): 22-26$.

[31] Niu T, Liu HL, Song Y et al. Study on decade change of climate shift from warm-dry period to warm-wet period over Tibetan Plateau. Journal of Applied Meteorological Science, 2005, 16(6): 763-771. [牛涛, 刘洪利, 宋燕等. 青藏高原气候 由暖干到暖湿时期的年代际变化特征研究. 应用气象学报, 2005, 16(6) : 763-771.]

[32] Wu SH, Yin YH, Zheng D et al. Climate changes in the Tibetan Plateau during the last three decades. Acta Geographica Sinica, 2005, 60 (1) : 3-11. [ 吴绍洪, 尹云鹤, 郑度等. 青藏高原近 30 年气候变化趋势. 地理学报, 2005, 60(1): 3-11.]

[33] Liu GF, Lu HL. Basic characteristics of major climatic factors on Qinghai-Tibet Plateau in recent 45 years. Geographical Research, 2010, 29(12): 2281-2288. [刘桂芳, 卢鹤立. 1961 2005 年来青藏高原主要气候因子的基本特征. 地理 研究, 2010, 29(12) : 2281-2288.]

[34] Lu SL, Xiao GH, Jia L et al. Extraction of the spatial-temporal lake water surface dataset in the Tibetan Plateau over the past 10 years. Remote Sensing for Land \& Resources, 2016, 28(3) : 181-187. [卢善龙, 肖高怀, 贾立等. 2000-2012 年青藏高原湖泊水面时空过程数据集遥感提取. 国土资源遥感, 2016, 28(3): 181-187.]

[35] Song C, Huang B, Ke L. Inter-annual changes of alpine inland lake water storage on the Tibetan Plateau: Detection and a- 
nalysis by integrating satellite altimetry and optical imagery. Hydrological Processes, 2014, 28(4) : 2411-2418.

[36] Lu S, Jia L, Zhang L et al. Lake water surface mapping in the Tibetan Plateau using the MODIS MOD09Q1 product. Remote Sensing Letters, 2016. DOI: 10.1080/2150704X.2016.1260178.

[37] Lu S, Jin J, Jia L et al. MODIS ( MOD09Q1)-derived lake water surface dataset for the Tibetan Plateau( 2000-2012). Science Data Bank, 2017, 2(2). DOI: 10.11922/csdata. 170.2016.0113. [卢善龙, 金继明, 贾立等. 基于 MODIS MOD09Q1 的青海、西藏湖泊水面数据集 (2000 2012 年). 中国科学数据, 2017, 2(2).]

[38] Huang C, Chen Y, Wu J. Mapping spatio-temporal flood inundation dynamics at large river basin scale using time-series flow data and MODIS imagery. International Journal of Applied Earth Observation \& Geoinformation, 2014, 26 ( 1): 350-362.

[39] Zhang Y, Li B, Zheng D. A discussion on the boundary and area of the Tibetan Plateau in China. Geographical Research, 2002, 21 (1) : 1-8. [ 张镱锂, 李炳元, 郑度. 论青藏高原范围与面积. 地理研究, 2002, 21(1):1-8.]

[40] Jiang QG ed. Study on remote sensing survey and ecological geological environment effects of Tibetan Plateau wetlands. Beijing: Geological Publishing House, 2012. [姜琦刚. 青藏高原湿地遥感调查及生态地质环境效应研究. 北京: 地 质出版社, 2012.]

[41] Liu C, Ge CH. Features and application of Remote Sensing Imaging Spectrometer (MODIS) remote sensing data from US Earth Observing System (EOS). Remote Sensing Information, 2000, (3) : 45-48. [刘闯, 葛成辉. 美国对地观测系统 (EOS) 中分辨率成像光谱仪 (MODIS) 遥感数据的特点与应用. 遥感信息, 2000, (3) : 45-48.]

[42] He J, Yang K. China Meteorological Forcing Dataset. Cold and Arid Regions Science Data Center at Lanzhou, 2011. DOI: 10.3972/westdc.002.2014.db. [何杰, 阳坤. 中国区域高时空分辨率地面气象要素驱动数据集. 寒区旱区科学数据 中心, 2011.]

[43] Chen Y, Yang K, Jie H et al. Improving land surface temperature modeling for dry land of China. Journal of Geophysical Research Atmospheres, 2011, 116, D20104. DOI:10.1029/2011JD015921.

[44] Liu S, Guo W, Xu J et al. The Second Glacier Inventory Dataset of China (Version 1.0). Cold and Arid Regions Science Data Center at Lanzhou, 2014. DOI:10.3972/glacier.001.2013.db.

[45] Guo N, Zhang J, Liang Y. Climate change indicated by the recent change of inland lakes in northwest China. Journal of Glaciology and Geocryology, 2003, 25(2) : 211-214. [ 郭铌, 张杰, 梁芸. 西北地区近年来内陆湖泊变化反映的气候 问题. 冰川冻土, 2003, 25(2): 211-214.]

[46] Wan W, Li H, Xie H et al. A comprehensive data set of lake surface water temperature over the Tibetan Plateau derived from MODIS LST products 2001-2015. Scientific Data, 2017, 4: 170095.

[47] Yao X, Liu S, Li L et al. Spatial-temporal variations of lake area in Hoh Xil region in the past 40 years. Acta Geographica Sinica, 2013, 68(7) : 886-896.

[48] Nanjing Institute of Geography and Limnology, Chinese Academy of Sciences ed. Distribution of lakes atlas in China. Beijing: Science Press, 2015. [中国科学院南京地理与湖泊研究所. 中国湖泊分布地图集. 北京: 科学出版社, 2015.]

[49] Wang SM ed. Chinese lakes inventory. Beijing: Science Press, 1989. [王苏民. 中国湖泊志. 北京: 科学出版 社, 1998.]

[50] Zheng MP ed. Salt lakes in the Tibetan Plateau. Beijing: Beijing Science and Technology Press, 1989. [郑绵平. 青藏高 原盐湖. 北京: 北京科学技术出版社, 1989.]

[51] Zheng XY ed. Salt lakes in China. Beijing: Science Press, 2002. [郑喜玉. 中国盐湖志. 北京: 科学出版社, 2002.]

[52] Shen G. Monitoring lake-level changes in the Qinghai-Tibetan Plateau using radar altimeter data (2002-2012). Journal of Applied Remote Sensing, 2013, 7(21): 073470.

[53] Yan L, Zheng M. The response of lake variations to climate change in the past forty years: A case study of the northeastern Tibetan Plateau and adjacent areas, China. Quaternary International, 2015, 371: 31-48.

[54] Li L, Shi XH, Shen HY et al. Cause of water level fluctuation in Qinghai Lake from 1960 to 2009 and its future trend forecasting. Journal of Natural Resources, 2011, 26(9) : 1566-1574. [李林, 时兴合, 申红艳等. 1960-2009 年青海湖水 位波动的气候成因探讨及其未来趋势预测. 自然资源学报, 2011, 26(9) : 1566-1574.]

[55] Liu BK, Wei XL, Du YE et al. Dynamics of Qinghai Lake area based on environmental mitigation satellite data. Pratacultural Science, 2013, 30(2) : 178-184. [刘宝康, 卫旭丽, 杜玉娥等. 基于环境减灾卫星数据的青海湖面积动态. 草 业科学, 2013, 30(2): 178-184.] 
[56] Tong K, Su F, Xu B. Quantifying the contribution of glacier meltwater in the expansion of the largest lake in Tibet. Journal of Geophysical Research Atmospheres, 2016, 121(19) : 11158-11173.

[57] Zhang G, Yao T, Xie H et al. An inventory of glacial lakes in the Third Pole region and their changes in response to global warming. Global \& Planetary Change, 2015, 131: 148-157.

[58] Yang RH, Yu XZ, Li YL. The dynamic analysis of remote sensing information for monitoring the expansion of the selincuo lake in Tibet. Remote Sensing for Land \& Resources, 2003, 15(2): 64-67. [杨日红, 于学政, 李玉龙. 西藏色林错湖面 增长遥感信息动态分析. 国土资源遥感, 2003, 15(2) : 64-67.]

[59] Pan HX, Wang SM. Spatial distribution of mineralized degree of lakes in China. Oceanologia et Limnologia Sinica, 2001, 32(2) : 185-191. [潘红胥，王苏民. 中国湖泊矿化度的空间分布. 海洋与湖沼，2001，32(2) : 185-191.]

[60] Dong SY, Xue X, Xu MH et al. Influence of climate change on water environment in the Qinghai-Tibet Plateau. Arid Land Geography, 2013, 36(5): 841-853. [董斯扬, 薛涃, 徐满厚等. 气候变化对青藏高原水环境影响初探. 干旱区地 理, 2013, 36(5): 841-853.]

[61] Li YT, LI XY, Cui BL et al. Trend of pan evaporation and its impact factors over Lake Qinghai basin from 1961 to 2007. J Lake Sci, 2010, 22(4) : 616-624. DOI: 10.18307/2010.0420. [李岳坦, 李小雁, 崔步礼等. 青海湖流域及周边地区 蒸发血蒸发量变化( 1961-2007 年) 及趋势分析. 湖泊科学, 2010, 22(4) : 616-624.]

[62] Liu M, Shen YJ, Zeng Y et al. Changing trend of pan evaporation and its cause over the past 50 years in China. Acta Geographica Sinica, 2009, 64(3) : 259-269. [刘敏, 沈彦俊, 曾燕等. 近 50 年中国蒸发孟蒸发量变化趋势及原因. 地 理学报, 2009, 64(3): 259-269.]

[63] Du J, Fang SB, Tang XP et al. Spatial and temporal changes of potential evaporation over the Nujiang River Basin in Tibet during 1981-2010. Progressus Inquisitiones de Mutatione Climatis, 2012, 8(1): 35-42. [杜军, 房世波, 唐小萍等. 1981-2010 年西藏怒江流域潜在蒸发量的时空变化. 气候变化研究进展, 2012, 8(1) : 35-42.]

[64] Du J, Bian D, Bao JH et al. Changes of pan evaporations and its impact factors over northern Tibet in 1971-2006. Advances in Water Science, 2008, 19(6): 786-791. [杜军, 边多, 鲍建华等. 藏北高原蒸发西蒸发量及其影响因素的 变化特征. 水科学进展, 2008, 19(6): 786-791.]

[65] Shen HY, Ma ML, Wang QC et al. Changes of pan evaporation and its impact on water resource in Qinghai plateau from 1961 to 2010. Journal of Meteorology and Environment, 2013, 29 (6) : 87-94. [ 申红艳, 马明亮, 汗青春等. 19612010 年青海高原蒸发亚蒸发量变化及其对水资源的影响. 气象与环境学报, 2013, 29(6) : 87-94.]

[66] Song C, Huang B, Richards K et al. Accelerated lake expansion on the Tibetan Plateau in the 2000s: Induced by glacial melting or other processes? Water Resources Research, 2014, 50(4) : 3170-3186.

[67] He YX, Yi GH, Zhang TB et al. The EVI trends and analysis of its driving factors in Red River Basin affected by the “corridor-barrier” function during 2000-2014. Acta Ecologica Sinica, 2018, 38(6) : 1-8. [何奕萱, 易桂花, 张廷斌等. 红 河流域“通道-阻隔”作用下 2000-2014 年植被 EVI 变化趋势与驱动力分析. 生态学报, 2018, 38(6) : 1-8.]

[68] Wang Q, Zhang TB, Yi GH et al. Tempo-spatial variations and driving factors analysis of net primary productivity in the Hengduan mountain area from 2004 to 2014. Acta Ecologica Sinica, 2017, 37(9) : 3084-3095. [王强, 张廷斌, 易桂花 等. 横断山区 2004-2014 年植被 NPP 时空变化及其驱动因子. 生态学报, 2017, 37(9) : 3084-3095.]

[69] Li CX, Yang TB, Tian HZ. Variation of West Kunlun Mountains glacier during 1990-2011. Progress in Geography, 2013, 32(4) : 548-559. [李成秀, 杨太保, 田洪阵. 1990-2011 年西昆仑峰区冰川变化的遥感监测. 地理科学进展, 2013, $32(4)$ : 548-559.]

[70] Yao T, Thompson L, Yang W et al. Different glacier status with atmospheric circulations in Tibetan Plateau and surroundings. Nature Climate Change, 2012, 2(9): 663-667.

[71] Yang K, Wu H, Qin J et al. Recent climate changes over the Tibetan Plateau and their impacts on energy and water cycle: A review. Global \& Planetary Change, 2014, 112(1): 79-91.

[72] Wu KP, Liu SY, Bao WJ et al. Remote sensing monitoring of the glacier change in the Gangrigabu Range, southeast Tibetan Plateau from 1980 through 2015. Journal of Glaciology and Geocryology, 2017, 39(1) : 24-34. [吴坤鹏, 刘时银, 鲍 伟佳等. 1980-2015 年青藏高原东南部岗日嘎布山冰川变化的遥感监测. 冰川冻土, 2017, 39(1): 24-34.]

[73] Li G, Lin H. Recent decadal glacier mass balances over the Western Nyainqentanglha Mountains and the increase in their melting contribution to Nam Co Lake measured by differential bistatic SAR interferometry. Global \& Planetary Change, 2017, 149: 177-190. 
[74] Li DP, Wang LP, Liu SY et al. Tupu analysis of the spatio-temporal glacier variations in the central and western Qangtang Plateau since the little ice age. Journal of Glaciology and Geocryology, 2009, 31(1): 40-47. [李德平, 王利平, 刘时银 等. 小冰期以来㒸塘高原中西部冰川变化图谱分析. 冰川冻土, 2009, 31(1): 40-47.]

[75] Wang YZ, Ren JW, Qin DH et al. Regional glacier volume changes derived from satellite data: A case study in the Qilian Mountains. Journal of Glaciology and Geocryology, 2013, 35(3) : 583-592. [王玉哲, 任贾文, 秦大河等. 利用卫星资 料反演区域冰川冰量变化的尝试——以祁连山为例. 冰川冻土, 2013, 35(3): 583-592.]

[76] Du J, Yang TB, He Y. Glaciers and lakes changes and climate response in the Selin Co Basin from 1990 to 2011. Journal of Arid Land Resources and Environment, 2014, 28(12): 88-93. [杜鹃, 杨太保, 何毅. 1990-2011 年色林错流域湖 泊一冰川变化对气候的响应. 干旱区资源与环境, 2014, 28(12): 88-93.]

[77] Neckel N, Kropáček J, Bolch T et al. Glacier mass changes on the Tibetan Plateau 2003-2009 derived from ICESatlaser altimetry measurements. Environmental Research Letters, 2014, 9(1): 014009(1-7).

[78] Ji Q, Yang TB, Li X. Relationship between glacier retreat and climate change in eastern Nyainqentanglha in the past 40 years. Journal of Arid Land Resources and Environment, 2015, 29(2): 166-171. [冀琴, 杨太保, 李霞. 近 40 年来念青 唐古拉山东段则普乡地区冰川与气候变化研究. 干旱区资源与环境, 2015, 29(2): 166-171.] 